\title{
microRNAs Make the Call in Cancer Personalized Medicine
}

\author{
Simone Detassis, Margherita Grasso, Valerio Del Vescovo and Michela A. Denti* \\ Laboratory of RNA Biology and Biotechnology, Centre for Integrative Biology, University of Trento, Trento, Italy
}

Since their discovery and the advent of RNA interference, microRNAs have drawn enormous attention because of their ubiquitous involvement in cellular pathways from life to death, from metabolism to communication. It is also widely accepted that they possess an undeniable role in cancer both as tumor suppressors and tumor promoters modulating cell proliferation and migration, epithelial-mesenchymal transition and tumor cell invasion and metastasis. Moreover, microRNAs can even affect the tumor surrounding environment influencing angiogenesis and immune system activation and recruitment. The tight association of microRNAs with several cancer-related processes makes them undoubtedly connected to the effect of specific cancer drugs inducing either resistance or sensitization. In this context, personalized medicine through microRNAs arose recently with the discovery of single nucleotide polymorphisms in the target binding sites, in the sequence of the microRNA itself or in microRNA biogenesis related genes, increasing risk, susceptibility and progression of multiple types of cancer in different sets

OPEN ACCESS

Edited by:

Simona Pisanti,

University of Salerno, Italy

Reviewed by:

Chandi C Mandal,

Central University of Rajasthan, India

Botao Zhao,

Shanghai University, China

*Correspondence:

Michela A. Dent

denti@science.unitn.it

Specialty section: This article was submitted to Molecular and Cellular Oncology, a section of the journal Frontiers in Cell and Developmental

Biology

Received: 30 June 2017 Accepted: 08 September 2017 Published: 22 September 2017

Citation:

Detassis S, Grasso M, Del Vescovo V and Denti MA (2017) microRNAs Make the Call in Cancer Personalized Medicine. Front. Cell Dev. Biol. 5:86. doi: 10.3389/fcell.2017.00086 of the population. The depicted scenario implies that the overall variation displayed by these small non-coding RNAs have an impact on patient-specific pharmacokinetics and pharmacodynamics of cancer drugs, pushing on a rising need of personalized treatment. Indeed, microRNAs from either tissues or liquid biopsies are also extensively studied as valuable biomarkers for disease early recognition, progression and prognosis. Despite microRNAs being intensively studied in recent years, a comprehensive review describing these topics all in one is missing. Here we report an up-to-date and critical summary of microRNAs as tools for better understanding personalized cancer biogenesis, evolution, diagnosis and treatment.

Keywords: microRNAs, personalized medicine, cancer, MiR-SNP, biomarker

\section{MICRORNA BIOGENESIS}

microRNAs are small non-coding RNAs described for the first time in 1993 (Lee et al., 1993). They are found in plants (Jones-Rhoades et al., 2006), animals and viruses (Grundhoff and Sullivan, 2011), with functions in RNA silencing and post-transcriptional regulation of gene expression. They also have a role in pathological processes including neurodegenerative diseases (Molasy et al., 2016; Reddy et al., 2016) and cancer (da Silva Oliveira et al., 2016; Mohammadi et al., 2016). microRNAs transcriptional units are present both in introns or exons of other genes and as independent ones (Godnic et al., 2013). They are transcribed mainly by RNA Polymerase II, capped and polyadenylated forming primary microRNAs (pri-microRNAs). A small group is generated by RNA Polymerase III. The pri-microRNA is processed in a precursor microRNA (premicroRNA) - about 70 nt-by RNase III Drosha and RNA-binding protein DGCR8 (Lee et al., 2003). Subsequently, the pre-microRNA is transported out of the nucleus via exportin-GTPase 
RAN system, where is further processed by Dicer producing the double-stranded microRNA of 22nt (Wilson et al., 2015). A complex made of AGO proteins is able to bind it and form the miRISC. Only one strand of the microRNA is loaded in the RISC complex, while the other (the passenger strand) is thought to be degraded. The RISC complex has an important post-transcriptional role in gene expression, regulating stability and turnover of mRNAs. The loaded microRNA can target mRNAs, exploiting its sequence complementarity. If the match is perfect the system leads to the mRNA degradation (Yekta et al., 2004), otherwise it impedes its translation (Ipsaro and JoshuaTor, 2015). Because of their short length, microRNAs, which usually bind the $3^{\prime}$ UTR of target mRNAs, are able to target several distinct mRNAs and, on the other hand, any given mRNA may present many binding sites for different microRNAs (Bartel et al., 2009).

\section{MICRORNA AND CANCER}

It has been widely reported that microRNAs are involved in many aspects related to cancer (Figure 1). Following the "hallmarks" of cancer (Hanahan and Weinberg, 2011) we can find many articles in which microRNAs play a role in each of these steps on the road of cancer biogenesis and progression. Here we describe some examples (Table 1).

1. Sustaining the proliferative signal. miR-27a-3p was shown to be associated with progression of nasopharyngeal cancer from patient samples and to be increased compared to healthy tissues. In vitro it promotes $5-8 \mathrm{~F}$ cell proliferation, migration and invasion targeting MAPK10 (Li and Luo, 2017). On the contrary, miR-545 was found decreased in colorectal cancer (CRC) in comparison to normal tissues and thus, its over-expression led to diminished proliferation and colony formation capacity (Huang and $\mathrm{Lu}, 2017$ ). Luciferase and western blot assay confirmed the in-silico prediction of miR545 targeting EGFR in CRC cell lines.

2. Evading tumor suppressors. Liu and colleagues (Liu Y. et al., 2017) showed how miR-19a binds directly the $3^{\prime}$ UTR of TIA1 mRNA, involved in stress granuli formation and in the apoptotic pathway, promoting cell proliferation and migration in CRC cells, boosting also tumor growth in xenograft mice.

3. Resistance to cell death. It has been reported that miR-29 is an endogenous regulator of MCL-1 protein expression, an antiapoptotic molecule, and it has been found down-regulated in cholangiocarcinoma cell lines (Mott et al., 2007). Similarly, miR-15a and miR-16-1, found deleted or down-regulated in the majority of chronic lymphocytic leukemias (CLLs), can directly negatively regulate BCL-2 in CLL. Their expression was described as inversely correlated to BCL2 expression in CLL and their over-expression may induce apoptosis in a leukemic cell line model through BCL2 repression (Cimmino et al., 2005).

4. Enabling replicative immortality. miR-130b 301b cluster is hypermethylated in prostate cancer cells and it was demonstrated how its expression restoration can replace senescence mechanisms reducing the malignant phenotype of prostate cancer cells (Chen et al., 2015; Ramalho-Carvalho et al., 2017). Similarly, miR-137 levels are significantly reduced in human pancreatic cancer leading to a defective senescence response. This small non-coding RNA targets KDM4A which expression contributes to avoid miR-137-induced senescence. Therefore, restoration of miR-137 expression it has been reported to promote senescence and dampen proliferation of pancreatic cancer cells (Neault et al., 2016).

5. Inducing angiogenesis. miR-135a is generally decreased in gastric cancer tissues compared to normal samples. It targets FAK which is an important regulator and effector of VEGF in tumor angiogenesis. It has been described that upon miR135a over-expression, the protein levels of FAK in gastric cancer cell lines decrease significantly. Therefore, it has been proposed that miR-135 inhibits tumor growth, migration, invasion and angiogenesis by targeting focal adhesion kinase (FAK) pathway (Cheng et al., 2017). Differently, miR-23 in lung cancer cells under hypoxic conditions is up-regulated in the secretome and directly targets prolyl hydroxylase 1 and 2, enhancing the accumulation of the hypoxiainducible factor- $1 \alpha$. Consequently, hypoxic lung cancer cells enhanced angiogenesis. In addition, it has been shown how secreted miR-23a also inhibits tight junction protein $\mathrm{ZO}-1$, thereby increasing vascular permeability and cancer trans-endothelial migration. Moreover, inhibition of miR-23a dampened angiogenesis and tumor growth in mice and miR23a found in sera of lung cancer patients positively correlated with proangiogenic activities (Hsu et al., 2017).

6. Activation of invasion and metastasis. Daugaard and colleagues demonstrated via RNA-seq analysis of formalinfixed paraffin embedded (FFPE) lung adenocarcinomas from patients with and without detectable metastasis disease, that down-regulation of miR-30a-3p and up-regulation of miR-210-3p were significantly associated with the presence of distant metastases (Kumarswamy et al., 2012; Daugaard et al., 2017). Microarray analysis and quantitative PCR by the Law laboratory identified and validated up-regulated miR-885-5p in liver metastases when compared to primary CRCs. Furthermore, over-expression of miR-885-5p in vitro led to cell migration, invasion and in vivo development of liver and lung metastases. miR-885-5p targets directly the $3^{\prime}$ UTR of CPEB2 which negatively regulates TWIST1, a well-known player in epithelial-mesenchymal transition (EMT) (Siu-Chi Lam et al., 2017). Alike, miR-9 may promote ovarian cancer metastasis targeting E-CADHERIN and upregulating N-CADHERIN and VIMENTIN, mesenchymal markers (Zhou et al., 2017).

7. Reprogramming energy metabolism. It is well-known that cancer cells are able to modify its metabolism favoring survival and proliferation. miR-7 has been demonstrated to decrease the usually up-regulated metabolic autophagy in pancreatic cancer cells via affecting LKB1-AMPK-mTOR signaling ( $\mathrm{Gu}$ et al., 2017). Another tumor suppressor microRNA is miR-1 which has been described to be down-regulated in CRC cell lines compared to normal colon epithelial cells. Moreover, over-expression of miR-1 decreases cancer cell proliferation 


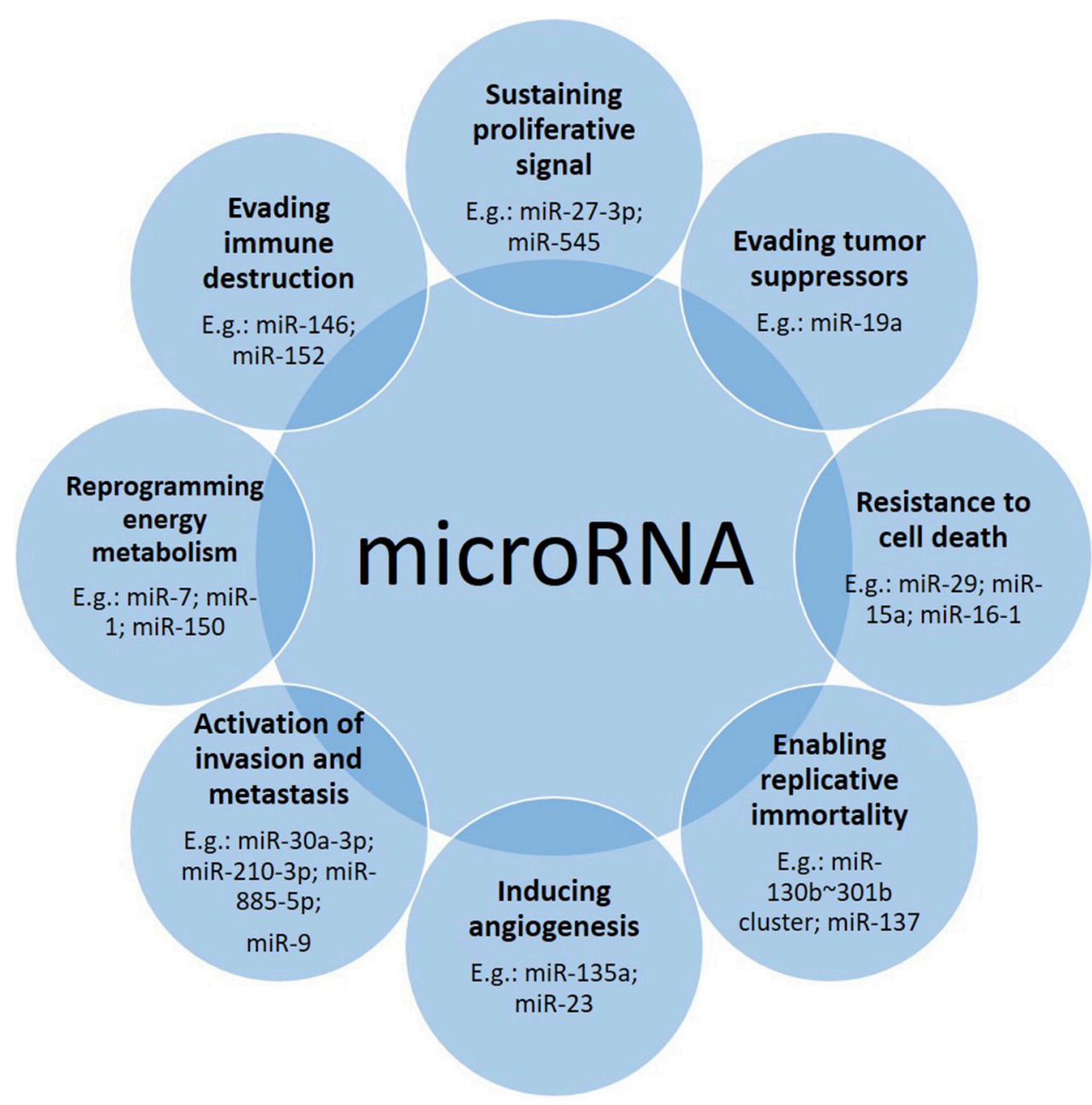

FIGURE 1 | Down- or up-regulation of microRNAs contribute to the cancer driving steps. Often one microRNA affects more than one hallmark, with one prevailing tissue-dependent mechanism.

dampening aerobic glycolysis, lactate production and glucose uptake in vitro targeting HIF- $1 \alpha$ and impacting SMAD3 pathway (Xu et al., 2017). On the contrary, high levels of miR-150 in glioma cells increased the Warburg effect, via the targeting of VHL $3^{\prime} \mathrm{UTR}$, facilitating in vivo tumor growth (Li et al., 2017).

8. Evading immune destruction. Khorrami and colleagues showed how over-expression of miR-146 in a CRC cell line cocultured with peripheral blood mononuclear cells extracted from healthy donors, increased $\mathrm{T}_{\text {reg }}$ frequencies and antiinflammatory cytokines like TGF- $\beta$ and IL-10, leading to an overall immune suppression in the tumor microenvironment (Rusca and Monticelli, 2011; Khorrami et al., 2017). On the other hand, miR-152 was shown to be decreased in gastric cancer cell lines as well as in human gastric cancer tissues. Restoration of its expression leads to enhanced $\mathrm{T}$ cells proliferation and effector cytokines production through the inhibition of the B7-H1/PD-1 pathway (Wang Y. et al., 2017).
In this network of complexity, it should be added that one microRNA, in view of its target promiscuity, could have multiple roles in different type of cancers. miR-21 is one of those microRNAs. It has been found to be an antiapoptotic factor in breast cancer (Si et al., 2007) and its suppression increased CASPASE3/7 enzymatic activities in human glioblastoma cells (Chan et al., 2005). Moreover, miR21 is able to sustain proliferative signal targeting PTEN, a well-known tumor suppressor, in cholangiocarcinoma ( $\mathrm{He} \mathrm{Q}$. et al., 2013; Wang L.-J. et al., 2015) and human hepatocellular carcinoma (Meng et al., 2007), inhibiting AKT and mTOR pathway which promotes cell survival and proliferation. miR21 is linked with PI3K/AKT pathway also via the inhibition of FOXO1 in large B-cell lymphoma (Go et al., 2015). It was also shown to target TPM1 which normally is considered a tumor suppressor gene, regulating microfilament formation and anchorage-independent growth in a breast cancer cell line (Zhu et al., 2007). In addition, in breast cancer, miR-21 has been reported to sustain EMT signaling and IL-6 levels 
TABLE 1 | Examples of microRNAs involved in the hallmark of cancer.

\begin{tabular}{|c|c|c|c|c|c|}
\hline Hallmark & microRNA & $\begin{array}{l}\text { De-regulation in } \\
\text { cancer }\end{array}$ & Target & Function & References \\
\hline \multirow[t]{2}{*}{ Sustaining proliferative signal } & miR-27-3p & $\begin{array}{l}\uparrow \text { in nasopharyngeal } \\
\text { cancer }\end{array}$ & MAPK10 & $\begin{array}{l}\text { Regulation of ERK1 and ERK2 } \\
\text { cascade }\end{array}$ & Li and Luo, 2017 \\
\hline & miR-545 & $\downarrow$ in colorectal cancer & EGFR & Signaling pathway & Huang and Lu, 2017 \\
\hline Evading tumor suppressors & miR-19a & $\uparrow$ in colorectal cancer & TIA1 & Major granule associated species & Liu Y. et al., 2017 \\
\hline \multirow[t]{2}{*}{ Resistance to cell death } & miR-29 & $\downarrow$ in cholangiocarcinoma & MCL-1 & $\begin{array}{l}\text { Regulation of apoptosis vs. cell } \\
\text { survival, and maintenance of viability }\end{array}$ & Mott et al., 2007 \\
\hline & $\begin{array}{l}\operatorname{miR}-15 a \\
\operatorname{miR}-16-1\end{array}$ & $\begin{array}{l}\downarrow \text { in chronic lymphocytic } \\
\text { leukemias }\end{array}$ & BCL-2 & Suppresses apoptosis & Cimmino et al., 2005 \\
\hline \multirow[t]{2}{*}{ Enabling replicative immortality } & $\begin{array}{l}\text { miR- } \\
\text { 130b } 301 b \\
\text { cluster }\end{array}$ & $\downarrow$ in prostate cancer & MMP2 & Matrix remodeling & $\begin{array}{l}\text { Ramalho-Carvalho et al., 2017; } \\
\text { Chen et al., } 2015\end{array}$ \\
\hline & miR-137 & $\downarrow$ in pancreatic cancer & KDM4A & Histone demethylase & Neault et al., 2016 \\
\hline \multirow[t]{2}{*}{ Inducing angiogenesis } & miR-135a & $\downarrow$ in gastric cancer & FAK & Non-receptor protein-tyrosine kinase & Cheng et al., 2017 \\
\hline & miR-23 & $\uparrow$ in lung cancer & $\mathrm{PH} 1 ; \mathrm{PH} 2 ; \mathrm{ZO}-1$ & $\begin{array}{l}\text { Alanine-Glyoxylate Aminotransferase; } \\
\text { Glyoxylate And Hydroxypyruvate } \\
\text { Reductase; Tight Junction Protein }\end{array}$ & Hsu et al., 2017 \\
\hline \multirow[t]{3}{*}{$\begin{array}{l}\text { Activation of invasion and } \\
\text { metastasis }\end{array}$} & $\begin{array}{l}\text { miR-30a- } \\
3 p\end{array}$ & $\downarrow$ in lung cancer & SNAl1 & $\begin{array}{l}\text { Induction of the epithelial to } \\
\text { mesenchymal transition, growth } \\
\text { arrest, survival and cell migration }\end{array}$ & Kumarswamy et al., 2012 \\
\hline & $\begin{array}{l}\text { miR-885- } \\
5 p\end{array}$ & $\uparrow$ in liver cancer & CPEB2 & Cell cycle progression & Siu-Chi Lam et al., 2017 \\
\hline & miR-9 & $\uparrow$ in ovarian cancer & E-CADHERIN & Calcium-dependent cell adhesion & Zhou et al., 2017 \\
\hline \multirow[t]{3}{*}{$\begin{array}{l}\text { Reprogramming energy } \\
\text { metabolism }\end{array}$} & $\operatorname{miR}-7$ & $\downarrow$ in pancreatic cancer & LKB1 & $\begin{array}{l}\text { Cell metabolism, cell polarity, } \\
\text { apoptosis and DNA damage } \\
\text { response }\end{array}$ & Gu et al., 2017 \\
\hline & miR-1 & $\downarrow$ in colorectal cancer & $\mathrm{HIF} 1 \alpha$ & $\begin{array}{l}\text { Activation of genes involved in } \\
\text { metabolism,angiogenesis,erythropoiesis } \\
\text { and glycolysis }\end{array}$ & Xu et al., 2017 \\
\hline & miR-150 & $\uparrow$ in glioma cells & VHL & $\begin{array}{l}\text { Regulates the hypoxia inducible } \\
\text { protein HIF in normoxic conditions }\end{array}$ & Li et al., 2017 \\
\hline \multirow[t]{2}{*}{ Evading immune destruction } & miR-146 & $\uparrow$ in colorectal cancer & IRAK1; TRAF6 & $\begin{array}{l}\text { Initiates innate immune response } \\
\text { against foreign pathogens; activation } \\
\text { of NFKB by TNFRSFs }\end{array}$ & $\begin{array}{l}\text { Rusca and Monticelli, 2011; } \\
\text { Khorrami et al., } 2017\end{array}$ \\
\hline & miR-152 & $\downarrow$ in gastric cancer & $\mathrm{B} 7-\mathrm{H} 1$ & $\begin{array}{l}\text { Costimulatory signal, essential for } \\
\text { T-cell proliferation and production of } \\
\text { IL10 and IFNG }\end{array}$ & Wang Y. et al., 2017 \\
\hline
\end{tabular}

affecting the tumor immune microenvironment (De MattosArruda et al., 2015). It is also true that some microRNAs may have a dual role in different cancer types, acting as tumor suppressor or onco-miR. miR-181a when overexpressed, was described in human glioma cells to induce apoptosis and dampen cell invasion (Shi et al., 2008) and migration in non-small cell lung cancer (NSCLC) (Cao et al., 2017). Interestingly, in human gastric cancer cells, miR-181a has been reported to be an onco-miR, promoting cell proliferation, wound healing invasion and EMT targeting RASSF6 (Mi et al., 2017). Thus, the complexity of the involvement of microRNAs in cancer is high and disentangling the dense net of RNAs interaction in order to build a complete and clear scenario will be a real challenge.

\section{MICRORNA AS CANCER BIOMARKERS}

As we have mentioned, it has become evident that microRNAs are involved in many aspects of cancer and because of their mechanism of action they control a big network of targets rather than few specific genes. This means that profiling microRNAs may give insights on complex processes hidden in numerous target genes, helping researchers to find new useful biomarkers. 
The definition of biomarker evolved with time and is not unique, but it could be summarized as "a characteristic that is objectively measured and evaluated as an indicator of normal biological processes, pathogenic processes, or pharmacologic responses to a therapeutic intervention" (Strimbu and Tavel, 2010). As a matter of fact, microRNAs possess most of the characteristics of the ideal biomarker, considering analytical criteria and clinical utility. They are specific to the pathology of interest, a reliable indication of the disease before clinical symptoms appear and sensitive to physiological or pathological changes. First demonstrations of the ability of microRNA expression patterns to be classifiers came in the first decade of 2000. Lu and colleagues implemented a bead-based microRNA profiling method in order to assess microRNA expression in normal and tumor tissues. Unexpectedly, they observed that precise pattern of microRNAs expression can, not only distinguish tumor origin, but also the degree of differentiation and classify poorly undifferentiated tumor tissues (Lu et al., 2005). Other evidences came from microRNA signatures that could discriminate between lung tumor tissues and correspondent nontumor tissues. Differential expression was also seen between adenocarcinoma (AD) and squamous cell carcinoma (SCC) tissues and between distinct prognosis (Yanaihara et al., 2006). A wider analysis on 22 different types of tumor tissue, revealed a signature of 48 microRNAs able to reach a classification accuracy $>90 \%$ (Rosenfeld et al., 2008). It is important to mention how NGS (Next Generation Sequencing) technologies revolutionized this field becoming progressively fundamental tools for personalized medicine (Schweiger et al., 2011). Even in microRNA studies these methods revealed completely new information which probably would not have been unveiled with standard techniques. In view of the big amount of data coming from NGS, new biomarkers have been discovered starting with an agnostic discovery platform methodology (Leidner et al., 2012; Wu et al., 2012) allowing researchers to be unbiased on their findings. There are some limitations that come together with the power of NGS, like costs, time-consuming experiments and management of big amount of data.

Pattern of microRNAs expression may be used to classify subpopulation of patients in order to choose the right strategy in the clinical practice. However, we have to be aware that the microRNA signatures as biomarkers are not always due to a direct biological mechanism, but also to indirect specific consequence of the disease. In the following paragraphs, we report some examples (Table 2 ).

\section{Biomarkers for Cancer Diagnosis and Sub-Typing}

Biomarkers can stratify patients upon different aims. One of the first clinical questions could be to understand whether the physician is facing a pathological condition. Therefore, discriminating between tumor tissues and non-tumor tissues is extremely important. The most recurrent example is miR21 which is over-expressed in many cancer types (Iorio et al., 2005, 2007; Volinia et al., 2006; Markou et al., 2008; Hezova et al., 2015; Kapodistrias et al., 2016; Parafioriti et al., 2016;
Calatayud et al., 2017; Chen et al., 2017; Cui et al., 2017; Nakka et al., 2017). The problem of using such microRNA as a biomarker is the absence of specificity. Therefore, signatures of a pattern of microRNAs are generally preferred to deliver a specific diagnosis. A nine microRNAs signature was able to discriminate between breast cancer tissues and normal cancer tissues collected by TCGA, with a high accuracy value and AUC of 0.995 (Xiong et al., 2017). Another example comes from the He group which found five microRNAs (miR-424, miR326, miR-511, miR-125b-2 and miR-451) able to provide high diagnostic accuracy of hepatocellular carcinoma starting from microRNA expression profiles of 377 hepatocellular carcinoma patients (Lu et al., 2017). As finding the pathological condition is relevant, the step forward is to understand what type of condition the clinician is facing. It is well-known that each cancer type is composed of several subtypes coming from different cellular origins and each of them has to be treated accordingly. Thus, it is important to discriminate among them and several studies pointed at this aim. A study on muscle-invasive bladder cancer in 2016 revealed a signature of 63 microRNAs able to discriminate between basal and luminal tumors and a 15 microRNAs based signature able to show basal and luminal tumors with apparent fibroblast infiltration (Ochoa et al., 2016). Similarly, Blenkiron and colleagues performed a model-based discriminant analysis for basal-like and luminal A breast tumors finding a set of microRNAs able to discriminate between those groups (Blenkiron et al., 2007). Another approach by the Jang lab exploited the expression of 1,733 microRNAs to build an unsupervised clustering in order to distinguish subtypes of pancreatic tumors. As result, they found 3 subtypes which could be associated with patient prognosis (Namkung et al., 2016). In lung cancer, in the data of the Volante lab, 10 microRNAs were able to distinguish between lung neuroendocrine (NE) tumors histotypes, 9 of which also discriminated between carcinoids and high-grade NE carcinomas (Rapa et al., 2015). In addition, combination of miR-21 and miR-205 was found to be able to distinguish lung AD from SCC (Lebanony et al., 2009) and this can be further improved with the analysis of miR-375 (Patnaik et al., 2015). As a matter of fact, we demonstrated the non-perfect reliability of miR-205 in discriminating AD vs. SCC lung cancer histotypes (Del Vescovo et al., 2011).

\section{Biomarkers for Cancer Progression}

Understanding the aggressiveness and progression of cancer via prognosis of the patient is of enormous relevance in clinical practice. microRNAs are able to predict patient prognosis in several types of cancer. Here show some examples from lung cancer. Let7 was found to be down-regulated in lung cancer in vitro and in vivo. A cohort of 143 lung cancer tissues was analyzed for the expression of let7 which resulted significantly down-regulated compared to normal tissues. Moreover, reduced let7 associates with higher disease stages and poor post-surgery survival and prognosis. Taking into account only the AD samples, these distinctions are maintained (Takamizawa et al., 2004). A wider analysis led to discover a 5 microRNAs signature (miR-221 and let7a protective, while miR-137, miR-372 and miR-182-3p risky) able to discriminate between NSCLC patients with higher 
TABLE 2 | (part 1) Examples of microRNAs as biomarkers.

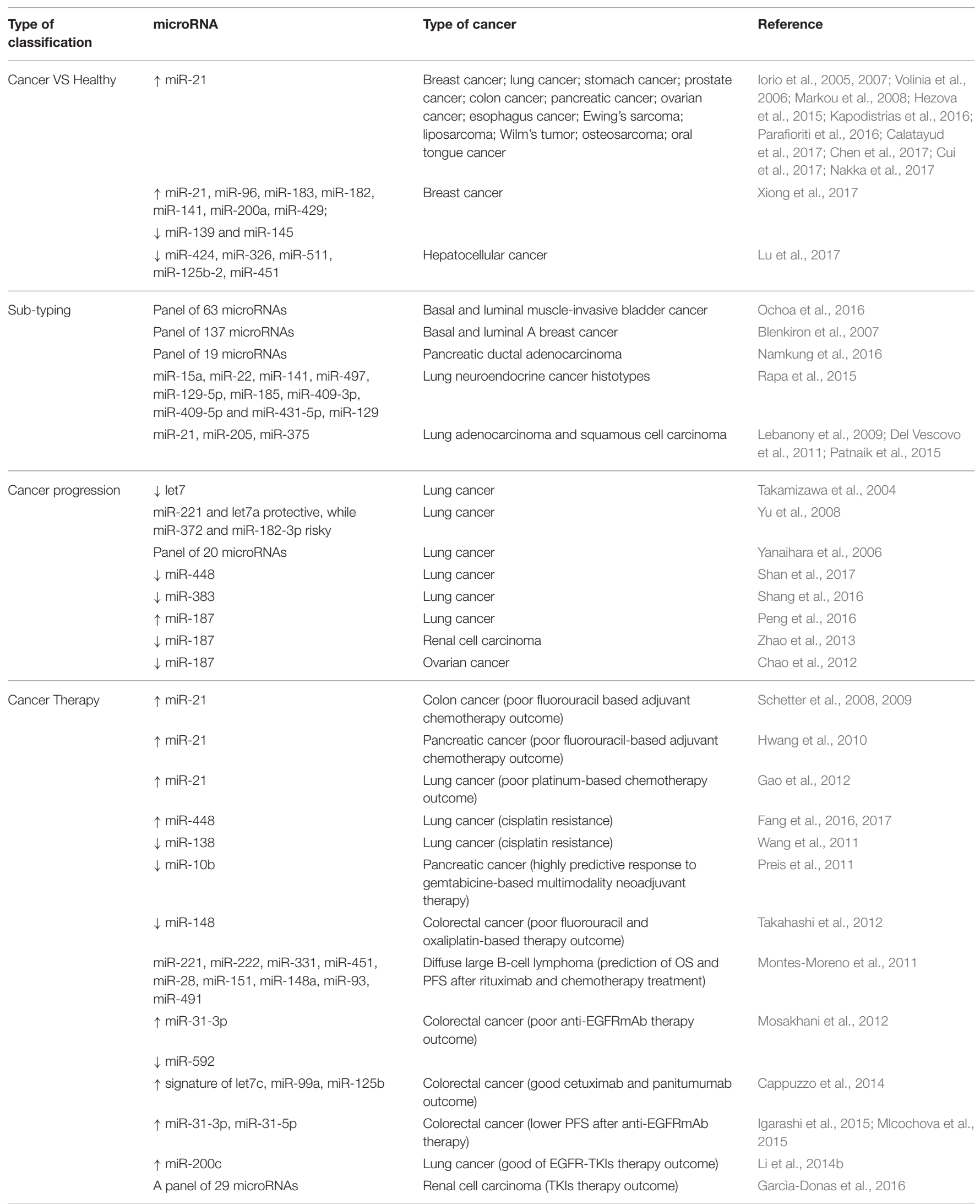


TABLE 2 | Continued

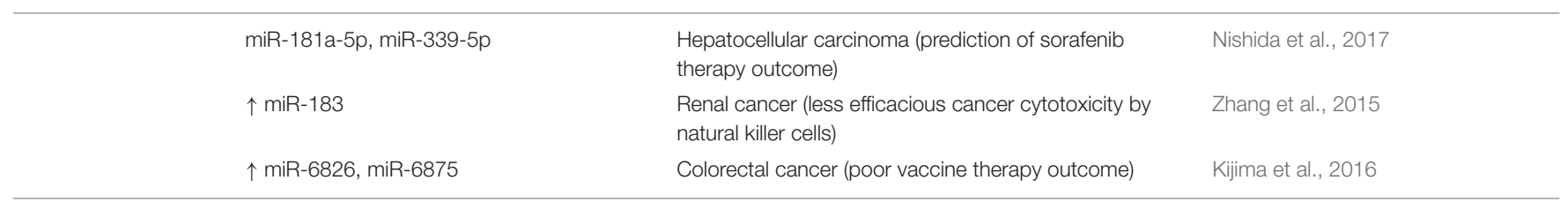

From diagnosis to the choice of therapeutic intervention.

or lower median overall survival (OS) independently from stage or histology. However, this signature is able to predict patient survival within histological type AD or SCC (Yu et al., 2008). With a similar strategy, a pattern of unique 15 microRNAs was able to discriminate between lung SCC and normal tissues, while a signature of 20 microRNAs was able to predict the OS (Raponi et al., 2009). Some of these microRNAs were more significant, like miR-146b which had the highest prediction score within 3 years, and some had already been linked to lung cancer in other studies like let-7 and miR-155 (Yanaihara et al., 2006). Interestingly, in all these studies, the different isoforms of let7 found, were down-regulated in patients with poor prognosis. More recent data show that low expression of miR-448 associates with lung SCC progression and poor patients overall survival (Shan et al., 2017). Reduced expression of miR-383 was found in NSCLC tumor tissues compared to adjacent non-tumorous samples and moreover, low miR-383 expression associated with poor post-operative prognosis (Shang et al., 2016). miR-448 and miR-383 are down-regulated, acting like tumor-suppressors, also in ovarian cancer ( $\mathrm{Lv}$ et al., 2015), hepatocellular carcinoma (Zhu et al., 2015; Chen et al., 2016), colorectal cancer (Li et al., 2016), breast cancer (Li et al., 2011), Hodgkin lymphoma (Paydas et al., 2016), glioma (He Z. et al., 2013; Xu et al., 2014) testicular carcinoma (Lian et al., 2010; Huang et al., 2014) and medulloblastoma (Li et al., 2013). Another study revealed that miR-187 expression was significantly increased in NSCLC tissue samples compared to adjacent non-lung tumor tissues and that this condition associated with TNM classification and shorter OS (Peng et al., 2016). Interestingly, miR-187 has been found down-regulated in clear cell renal cell carcinoma cells (Zhao et al., 2013) but up-regulated in ovarian cancer cells (Chao et al., 2012). However, in both cases the studies agree with what occurs in lung cancer, where low miR-187 level of expression is associated with poor patient survival.

\section{Biomarkers for Cancer Therapy}

As a consequence of the intricacy of underlying driving mechanisms of cancer, therapeutic efficacy of a single treatment can change depending on the patient and its type of cancer. microRNAs have been associated to, and also predictive of, therapeutic outcome. Here we report cases of some of the main standard cancer treatments.

miR-21 seems to be a general signal for chemotherapy resistance. In 2008, Schetter and colleagues found that miR21 expression, in typical colon $\mathrm{AD}$ from patients treated with fluorouracil based adjuvant chemotherapy, is higher in patients with a poor therapy outcome (Schetter et al., 2008, 2009). Similar results were obtained for pancreatic cancer (Hwang et al., 2010). Even in lung cancer, high-expression of miR-21 was associated with chemotherapy resistance in tissues of patients who had undergone platinum-based chemotherapy treatment (Gao et al., 2012). It was shown that A549/DDP lung AD cell line has a lower expression of eIF3a compared to its parental cell line, and it displays chemoresistance to cisplatin. miR-488 targets the $3^{\prime}$ UTR of eIF3a transcript enhancing sensitivity to the treatment and inhibiting cell proliferation, migration and invasion (Fang et al., 2016, 2017). Another study reported an increased sensitivity of A549/DDP cells to cisplatin after up-regulation of miR-138. The excision repair cross-complementation group 1 (ERCC1) was targeted by miR138 and the result was the down-regulation of the protein correlating with increased levels of miR-138 in A549/DDP cells (Wang et al., 2011). In another study on pancreatic ductal $\mathrm{AD}$, patients with resectable or locally advanced disease showed relative low miR-10b expression associated with highly predictive response to gemtabicine based multimodality neoadjuvant chemoradiotherapy. Moreover, by logistic regression, low miR$10 \mathrm{~b}$ expression was able to predict surgery efficacy. miR-10b levels demonstrated significant ability in survival prediction (Preis et al., 2011). In CRC, miR-148 expression had a potential for predicting therapeutic efficacy of 5-fluorouracil and oxaliplatin in patients with stage IV colorectal cancer, as low levels of this microRNA associated with bad therapeutic response (Takahashi et al., 2012). Sensitivity to cisplatin treatment is, at least partially, regulated by miR-488 which targets eIF3a.

Besides chemotherapy, targeted therapy is an important standard of care for several tumors. Even in this field, microRNAs may be helpful. For diffuse large B-cell lymphoma (DLBCL), combination between chemotherapy and immunotherapy with rituximab has become a standard treatment. A 9 microRNAs signature was able to predict both OS and progression free survival (PFS) in DLBCL patients (Montes-Moreno et al., 2011). In a cohort of metastatic colorectal cancer patients wild type for KRAS and BRAF, a miR-31-3p up-regulation and miR592 down-regulation were found associated with poor response to anti-EGFRmAb (Mosakhani et al., 2012). An Italian study reported a signature of three microRNAs (miR-let7c, miR99a, and miR125b) able to predict EGFR monoclonal antibody therapy outcome in colorectal cancer patients. Indeed, highlevel of signature expression showed a good discrimination capacity for patients which were more responsive to cetuximab or panitumumab compared to low responsive patients (Cappuzzo et al., 2014). In two independent studies, miR-31 was found to be associated with PFS after administration of anti-EGFRmAb in metastatic colorectal cancer patients. Mlchocova and colleagues 
found both miR-31-5p and $-3 p$, while Shinomura group only miR-31-5p, to be higher in patients with lower PFS compared to those with low levels of the microRNA (Igarashi et al., 2015; Mlcochova et al., 2015). microRNAs have been discovered to be predictive also of kinase inhibitors efficacy in hepatocellular carcinoma, renal cell carcinoma and NSCLC (Li et al., 2014b; Garcìa-Donas et al., 2016; Nishida et al., 2017).

An emerging field in cancer treatment is immunotherapy. Some studies describe microRNAs as biomarkers of immunotherapy efficacy. In a report on 82 renal cancer patients and 19 healthy individuals, miR-183 has been found up-regulated in sera associated to less efficacious cancer cytotoxicity by natural killer cells, which are the effectors of the IL-2 immunotherapy (Zhang et al., 2015). Nagano group described that miR-6826 and miR-6875 can be good predictor of vaccine treatment efficacy in metastatic CRC, where high expression in plasma of two microRNAs was associated with poorer prognosis (Kijima et al., 2016).

\section{CIRCULATING MICRORNAS}

Over the last two decades, it has been demonstrated that a substantial number of microRNAs are present outside cells in blood and other body fluids, the so-called "circulating microRNAs" (c-microRNAs). C-microRNAs have been reported to be very stable under harsh conditions and able to survive high temperatures, extreme $\mathrm{pH}$, and RNase activity. As reviewed by Makarova and colleagues (Makarova et al., 2016) they are often found in association with small membranous particles (extracellular vesicles) and mostly with RNA-binding proteins (Ago2, HDL, etc.). The extracellular vesicles (EV) are represented by a various population of membranous particles with different origins and sizes. Microvesicles originate through the budding of the plasma membrane and have a size around 100-1,000 $\mathrm{nm}$. Exosomes, around 40-100 nm in size, are generated after the fusion of multivesicular bodies with the plasma membrane. The presence of these different carrier options leads researchers to think of selective microRNA sorting and secretion processes, not excluding stochastic (non-selective) ones. Moreover, the pool composition of the microRNAs is different intra- and extracellularly. Unfortunately, the exact mechanisms underlying these processes have to be discovered yet. Even though extracellular vesicles biogenesis is varied, only ceramide-dependent mechanism has been reported as one of the responsible for microRNA secretion so far (Kosaka et al., 2010). About sorting, it has been suggested that the affinity between the RNA and the raft-like membrane regions of the multivesicular bodies (MVBs) can guide it (Janas et al., 2015). In another study, Squadrito et al. (2014) reported that sorting of microRNAs to exosomes is partially regulated by the changes in expression of the targets inside the cell. The finding of a different microRNA sorting in exosomes depending on the KRAS status (Cha et al., 2015), adds concrete value on the selective sorting hypothesis. In 2013, SànchezMadrid group (Villarroya-Beltri et al., 2013) performed several microarrays analyses of activation-induced changes in the
microRNA and mRNA profiles among T-lymphoblasts and their exosomes. They obtained a discordance between intracellular and extracellular microRNA and mRNA pool composition, demonstrating once again that the sorting into exosomes is not-at least completely-passive. Interestingly, they reported a short sequence motif (GGAG) enriched in exosomal microRNAs. Among the many heterogeneous nuclear ribonucleoproteins (hnRNPs) that precipitated with intracellular and exosomal microRNAs, only hnRNPA1 and hnRNP2B1 seemed to bind exclusively the latter. Another study demonstrated that Vps4A, a key regulator of exosomes biogenesis, seemed to regulate the sorting of oncogenic and oncosuppressive microRNAs in exosomes, favoring the inclusion of the first ones (Wei et al., 2015). Furthermore, it has been described how, in B cells, $3^{\prime}$ end adenylated microRNAs appear to be enriched in cells compared to $3^{\prime}$ end uridylated isoforms which are more present in exosomes (Koppers-Lalic et al., 2014). What remains really unclear is the mechanism of sorting, if present, and of secretion of AGO-microRNA complexes. To date, the study reported by Turchinovich and colleagues, leads to think that the majority of these complexes is freed in a non-selective manner, because of the positive correlation between the content of c-microRNA in culture media and the increase of cell death (Turchinovich et al., 2011). Moreover, the Cayota group described via RNAseq analysis, how expression values of individual microRNAs in intracellular fractions of MCF-7 cells after a certain threshold, correlated directly with extracellular values, suggesting a passing mechanism of release also for extracellular vesicles related microRNAs (Tosar et al., 2015). However, these conclusions do not wipe out at all the possibilities of a parallel selective secretion.

The presence of putative precise processes underlying cmicroRNAs suggests that they could have an intriguing role in cell-cell communication. For instance, it was demonstrated that microRNAs enriched in extracellular vesicles derived from bone marrow mesenchymal stem cells can be absorbed by tubular epithelial cells resulting in the inhibition of expression of the known targets (Collino et al., 2010). Furthermore, as it has been reviewed (Neviani and Fabbri, 2015), c-microRNAs can influence cancer cells and their surrounding environment both targeting mRNAs and functioning as receptor-like systems. Much of the data supporting this way of cell-cell communication is done through in vitro systems, pushing for new validating studies in vivo which may confirm this hypothesis. One of the unclear point which can be argued is whether the actual amount of c-microRNAs is enough to drive expression changes in recipient cells in vivo. Some studies report that the average amount of microRNAs in exosomes is about 1 unit per exosome (Chevillet et al., 2014; Guzman et al., 2015). This very low amount may lead to some skepticism around the role of cmicroRNAs in cell-cell communication. However, extracellular vesicles associated microRNAs are a small percentage of the total pool of c-microRNAs (Arroyo et al., 2011) and in addition, this semi-quantitative reasoning is far too simplistic, not taking into account, for example, the accumulation of microRNAs in recipient cells and, being a median measure, doesn't consider the content heterogeneity of extracellular vesicles. 
Not only microRNAs from tissue can be used to create pattern of signatures able to classify group of patients but also c-microRNAs from liquid biopsies are becoming an increasing source of information (Chen et al., 2008). c-microRNAs as biomarkers have some advantages like great stability, resistance to ribonucleases and to severe physicochemical conditions in body fluids, increasing the feasibility of their use in clinical applications (Mitchell et al., 2008). Another important aspect is the compliance of the patients. Indeed, c-microRNAs are extracted from several body fluids coming from liquid biopsies, which are much less invasive and painful for the patients compared to the standard methods. Moreover, the cost and time for the processing is lower than non-liquid samples, promising big step toward the implementation of personalized medicine. Thus, the interest of the scientific community has grown intensively as demonstrated by the number of articles published in recent years at the entry "circulating microRNAs cancer biomarker" on PubMed $(2012 \rightarrow 86 ; 2013 \rightarrow$ 148; 2014 $\rightarrow 188 ; 2015 \rightarrow 239 ; 2016 \rightarrow 201)$. Moreover, there are some reviews which try to collect as much as possible the huge amount of information on circulating microRNAs as cancer biomarkers (Del Vescovo and Denti, 2015; Armand-Labit and Pradines, 2017; Matsuzaki and Ochiya, 2017; Zhao et al., 2017).

\section{MIRSNP}

microRNAs exert their function through an interaction with seed sequence on either $3^{\prime}$ UTR, 5'UTR or the coding sequence of a target mRNA. The hybridization between the two RNAs follows the Watson-Crick base pairing rules and thus it is guided by the formation of a stabilized double strand structure. Thus, when even single nucleotide changes occur in the sequence of either of the two interactors (miRSNP), the stability of the contact is affected and so is the functional outcome. Indeed, single nucleotide polymorphisms (SNPs) can affect microRNA expression and function and they can be present in the sequence of the microRNA or on its target genes (Figure 2). SNPs may be present also in the sequence of genes involved in the biogenesis of microRNAs, thus affecting their level of expression. These changes can influence the abovementioned patterns of microRNAs, creating completely new classes of patients based on association to risk of cancer or prediction to therapy. Moreover, as reviewed by Del Favero group, it should be considered that SNP density is higher in the flanking region of the microRNA sequence compared to microRNA genes themselves and mature form of microRNAs has lower SNP density than the pre-microRNA. Interestingly, the seed sequence has the lowest SNP density, highlighting their evolutionary and functional importance (Cammaerts et al., 2015).

In literature, there are numerous reports describing cancer risk association with SNPs related to microRNAs life. In a meta-analysis by Liu and colleagues (Liu H. et al., 2017), conducted on ten studies with 6,000 cases and 7,664 controls, a significant association of miR-608 rs4919510 polymorphism with decreased cancer risk via recessive model (CC vs. GG +
GC) was found. Interestingly, the same polymorphism has been already described to predict the clinical outcome in patients with different cancer types (Lin et al., 2012; Zheng et al., 2013; Pardini et al., 2015). As mentioned above, SNPs associated with microRNAs can alter several of their usual processes. One of the most common alteration is the degree of target suppression. rs73239138 polymorphism in miR-1269 was associated with increased susceptibility to hepatocellular carcinoma (HCC) and HBV-related HCC in a positive dominant model where genotypes with the A allele increased the risk to cancer (Min et al., 2017). It was shown that in HCC cell lines the over-expression of the miR-1269 variant led to a decreased inhibition of cell growth compared to the over-expression of the wild type microRNA. The authors confirmed the biological outcome demonstrating that the polymorphism on miR-1269 produced a dampened suppression of pErK1/2, SPATS2L and LRP6 compared to the wild type variant, where the last two genes showed to have a 3'UTR binding site for miR-1269. In a study on an Indian population (Sibin et al., 2017), miR-196a 2 expression varied with age, tumor grade and tumor type among glioma patients' tissues but not with different genotype of the microRNA. However, they found a significant difference in the expression of its mRNA target HOXC8 depending on different genotypes where CC and TT showed decreased and increased expression, respectively. Remarkably, out of 72 sample pairs of tumor tissues and blood samples, $19,44 \%$ showed different genotype of miR-196a2 in the tissue compared to the blood suggesting a critical role in tumorigenesis and in changing of tumor grade. Other evidences pointed out the importance of polymorphisms altering the ability of the microRNAs to post-transcriptionally inhibit gene expression of their target in colorectal (Liu Y. et al., 2016) and gastric cancer (Liu C. et al., 2016). Along with a negative effect of a SNP on microRNA sequence, this variation may lead also to positive effects, increasing binding capacity of the microRNA to its target (Gong et al., 2012). To the best of our knowledge, there are no reports of this scenario in cancer yet, neither in vitro nor in vivo.

Undoubtedly, variations in the sequence of microRNAs can also affect their maturation. Bioinformatic analysis of Gibbs free energy on the structure of the miR-146a stem loop showed that the $G$ allele of the rs2910164 polymorphism increased the stability factor of the overall structure, suggesting that, the association between the $\mathrm{C}$ carrier allele in the Iranian population under study may correlate with lower expression of miR-146a and thus higher incidence of the presence of its target Her2 in breast cancer (Meshkat et al., 2016). Indeed, miR-146 is significantly higher in triple-negative breast cancer compared to non-triple-negative breast cancer (Garcia et al., 2011). The already mentioned polymorphism on miR-196a2 was associated in other cancer studies to the microRNA maturation, changing the miR-196a2 expression (Hu et al., 2008, Hoffman et al., 2009). Another common scenario is the presence of a polymorphism in the microRNA binding site of an mRNA target. In a study on 325 colorectal cancer (CRC) patients and 977 normal individuals, the polymorphism rs7930 in the $3^{\prime} \mathrm{UTR}$ of TOMM20 was found to be associated with CRC susceptibility and the G allele described as the risk allele. Via in silico target analyses, miR-4273-5p was 


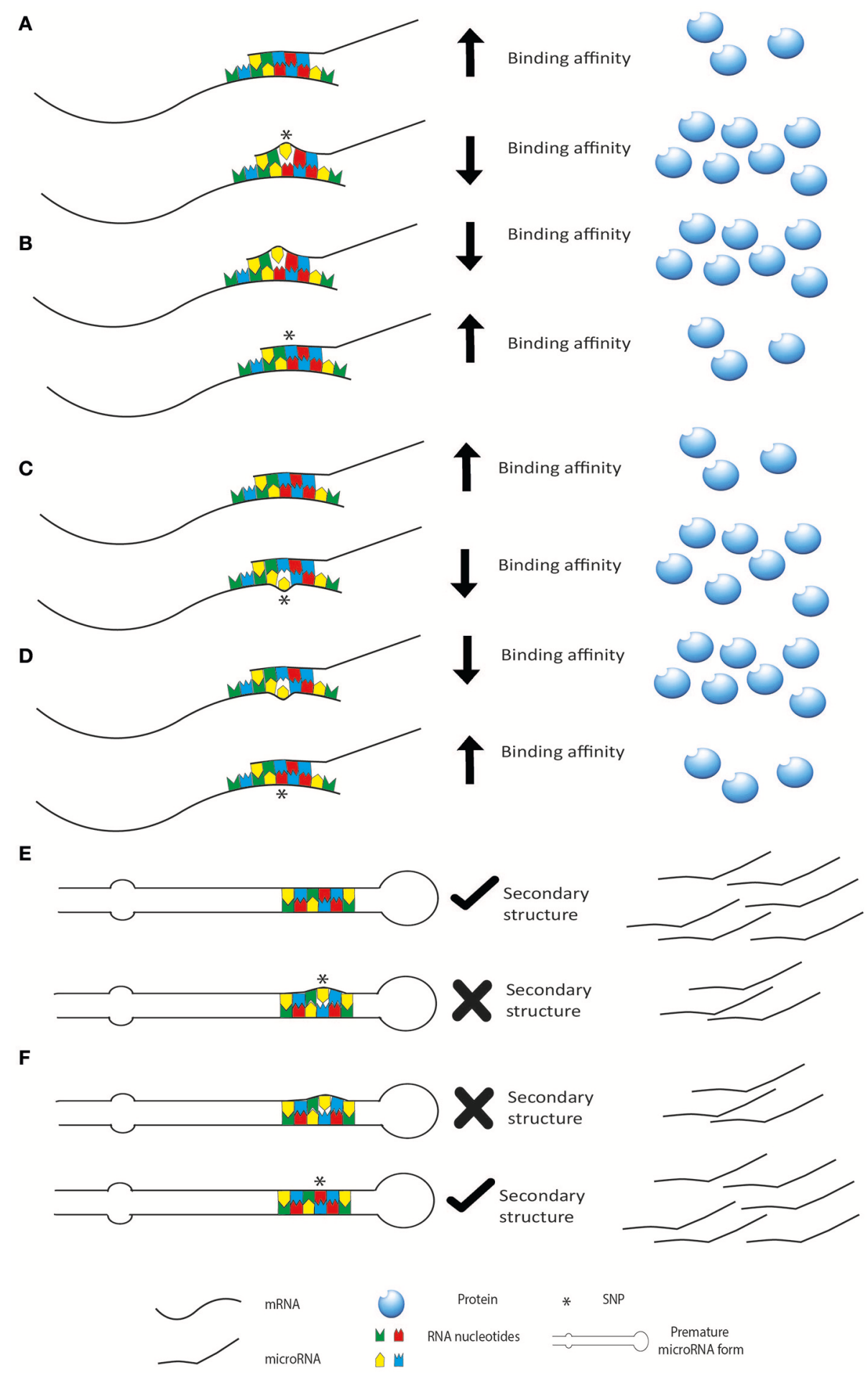

FIGURE 2 | miRSNP can affect microRNA biogenesis and activity. SNPs may be present on the microRNA decreasing (A) or increasing (B) its binding affinity for the target mRNA. SNPs may be present in the binding site of a target mRNA decreasing (C) or increasing (D) binding affinity (or creating new binding sites). In this last scenario are represented also SNPs in genes of the microRNA biogenesis machinery. These SNPs usually affect the regulation of the genes increasing or decreasing binding affinity of post-transcriptional regulators like microRNAs. SNPs may also affect the secondary structure of premature forms of the microRNAs decreasing (E) or increasing (F) their maturation. 
predicted to interact with rs7930. Validation by luciferase assay in human CRC cell lines demonstrated that the $\mathrm{G}$ allele plasmid did not have any effect on the reporter compared to a stronger effect of the A allele plasmid. Moreover, cell lines with the AA genotype showed a considerably stronger dampen in TOMM20 levels than those with the AG genotype (Lee et al., 2016). On two stages study made of 2347 cases and 3390 controls in total, Ke and colleagues found that the polymorphism rs1062044 on the sequence of LAMC1 produces an increased risk of colorectal cancer in the GA genotype compared to GG. Moreover, it decreases the ability miR-423-5p to bind LAMC1 in CRC cancer cell lines (Ke et al., 2017). The presence of a polymorphism on the binding site could also lead to a positive effect, thereby creating a new illegitimate binding site. Bartel group found that polymorphism SNP34091 in the 3'-UTR of MDM4 creates a new binding site for miR-191 in ovarian cancer (Wynendaele et al., 2010).

Polymorphisms on genes involved in the microRNA biogenesis can also have an impact on cancer progression. Mullany and colleagues, through RNA-seq and GWAS analysis of colon cancer tissues, found 24 microRNAs which were deregulated in the presence of SNPs significantly associated with altered mRNA expression or cancer risk. In particular, rs2740349 (GEMIN4) and rs235768 (BMP2) were shown to be associated with microRNA expression variation, with upregulation corresponding to the variant genotypes (Mullany et al., 2016). Interestingly, this up-regulation is associated with a down-regulation of the mRNAs of biogenesis genes, implicating new roles for these genes or other mechanisms of microRNA expression influence. In addition, Rotunno and colleagues found that RNASEN/rs640831, present in the GTACCT haplotype was associated with variation in expression of 56 microRNAs, both up- and down-regulated (Rotunno et al., 2010). One mechanism of action of these SNPs is the change in binding affinity of a regulator of the transcript like a microRNA. Jiang and colleagues genotyped 24 SNPs in a cohort of 878 breast cancer patients and 900 controls. They found that polymorphism rs417309 is associated with higher breast cancer risk (Jiang et al., 2013). Moreover, this SNP is placed on the $3^{\prime}$ UTR of the DGCR8 mRNA, affecting the binding ability of miR-106b and miR-579. However, the imperfect relationship between up-/down-regulation of microRNA biogenesis-related genes and up-/down-regulation of microRNAs, suggests a series of effects which are far to be completely clear and understood.

Behavioral changes of microRNAs upon SNPs can also affect the performance of cancer drugs. Pharmacogenomics studies how single genome or transcriptome variations can affect pharmacokinetics (PK) and dynamics (PD). A lot of attention has been drawn to microRNAs as possible players in this area. The contribution of microRNAs to PK and PD has been studied also via bioinformatic tools. Some genes are specific to $\mathrm{PK}$, some to $\mathrm{PD}$, whereas others to both. In silico data hint to a higher relevance of post-transcriptional regulation by microRNAs on PD unique genes compared to PK unique genes (Rukov et al., 2011). As a matter of fact, the latter show on average a shorter $3^{\prime}$ UTR with a less dense presence of predicted target binding site for microRNAs, compared to the former. Among some genes coding for drug metabolizing enzymes (DMEs), transporters and nuclear receptors, CYP1A2, CYP2B6, CYP2D6, CYP3A4, NR1I2, and UGT2B7 were sequenced for their $3^{\prime}$ UTR in a population of 30 South Africans (Swart and Dandara, 2014). 40 out of 52 SNPs detected were predicted to potentially create or abolish microRNA binding sites, thus affecting regulation capacity and expression of those genes. Despite the low number of patients enrolled, this study highlights once more the engagement of microRNAs in pharmacogenomics. Therefore, an increasing interest in creating web tools to analyze miRSNP and drugs has grown.

Mir2Drug is a database able to calculate the influence of miRSNP in drug efficiency. It considers the sequence $30 \mathrm{bp}$ upand downstream a known SNP in the $3^{\prime}$ UTR of target genes, and calculates all the predicted binding sites for microRNAs in that region, analyzing the change in free energy from wild type to variant genotype. Upon significant differences, Mir2Drug associates these SNPs as either direct or indirect drug targets. Therefore, it provides comprehensive annotation information on miRSNP belonging to drug target genes (Wang X. et al., 2017).

SMiR-NBI is another bioinformatic tool available on the web, which provides insights on possible pharmacogenomic biomarkers characterized by microRNAs, comprehending a network connecting small molecules to microRNAs regulation (Li et al., 2014a). This growing interest on miRSNP and pharmacogenomics comes from several works and here we try to review examples from different cancer types. A standard of care therapy for advanced lung cancer patients is the platinumbased chemotherapy. This kind of therapy leads to a spectrum of toxicities with different degree of severity. A study of Fang et al. (2016) found that the polymorphism rs2042553 of miR5197 significantly associates with severe toxicity after platinumbased treatment. Moreover, miR-605 polymorphism rs2043556 was associated with hepatotoxicity, while miR-27a rs895819 was related to gastrointestinal toxicity. Platinum-based therapies are often combined with other drugs like gemcitabine or paclitaxel. Geng et al. (2016) studied the effect of different regimen of chemotherapy based on cisplatin plus paclitaxel, gemcitabine or Changchun vinorelbine, in a cohort of advanced NSCLC patients. They found that polymorphism rs11077 in XPO5, a transport factor involved in the export of pre-microRNAs from the nucleus to the cytoplasm, is associated in AA genotype to a worse prognosis in a chemotherapy regimen compared to the AC genotype. Human Pregnane X Receptor (PXR) induces expression of DMEs, thus it can potentially influence the efficacy of several anticancer drugs. In a study on 96 Indian breast cancer patients (Revathidevi et al., 2016), genomic DNA from blood samples was sequenced for PXR $3^{\prime}$ UTR. Among 12 SNPs already reported in several databases, 5 SNPs were observed and in particular, for SNPs rs 3732360 and rs3732359 the proportion of the mutant allele is higher compared to the wild type in the studied population. These two polymorphisms conferred a new binding site for miR$500 \mathrm{a}-3 \mathrm{p}$ and decreased the binding of miR-532-3p which is known to play a role in doxorubicin cardiotoxicity (Wang J.-X. et al., 2015). In fact, the observed SNPs either created new binding sites for microRNAs, or abolished some of them, or strengthen or dampened the binding capacity of others. 
Therefore, overall regulation of PXR could be affected impacting on the metabolism of drugs. As a matter of fact, microRNA predicted to be influenced by these SNPs are also involved in treatment efficacy and doxorubicin cardiotoxicity, as pathway analysis revealed. Even in non-solid tumors microRNA variation may impact on treatment efficacy and toxicity. Lòpez-Lòpez and colleagues studied possible associations between miRSNP and adverse reactions after methotrexate administration in Acute Lymphoblastic Leukemia (ALL) (Lopez-Lopez et al., 2014). They showed that SNP rs639174 in DROSHA is associated with vomit during consolidation of methotrexate treatment, as well as rs56103835 in pre-miR-453. Moreover, rs12894467 in pre-miR300 is associated with hepatic toxicity and hyperbilirubinemia in induction. However, the same group found that none of the miRSNP genotyped in a Spanish population of 152 ALL affected children, is associated with Vincristine-related neurotoxicity (Lopez-Lopez et al., 2016), highlighting how microRNAs are not involved randomly in every process, but they are selectively and directly responsible or indirectly involved in some divergent mechanism.

It is worth mentioning that also big sequence changes like INDELs in microRNAs related genomic regions can have an impact on how drugs are affected by human body and vice versa. Garcia-Ortì et al. (2012) found 19 microRNAs associated with gene copy number variations in genomic regions where they are located, in acute myeloid leukemia (AML) cells. 4 out of 19 had NF1 as a potential target gene but only miR-370 was then validated. Patients analysis showed that NF1 down-regulation by either miR-370 over-expression or NF1 gene deletion is common in AML. Thus, considering that NF1 deficiency leads to RAS activation, patients with over-expression of miR-370 may potentially take advantage from RAS or mTOR inhibitors (Parkin et al., 2010). Another study (Bruhn et al., 2016), pinpointed that different lengths in the $3^{\prime}$ UTR ATP binding cassette (ABC) membrane transporter P-gp (ABCB1) may alter the presence of several microRNA binding sites. Actually, imatinib resistant leukemia cell lines expressed shorter $3^{\prime}$ UTR potentially losing some regulating sequences. Indeed, the shortening of ABCG2 (another ABC transporter) 3'UTR removes miR-519c binding site, therefore contributing to drug resistance (To et al., 2009).

\section{LIMITATIONS OF MICRORNAS AS TOOLS FOR PERSONALIZED MEDICINE}

microRNAs are intensively studied as tools for personalized medicine because they encompass many ideal characteristics for fast and robust analysis, which is needed in clinical practice. As a matter of fact, they are generally stable due to protein based carriers or EVs engulfment. Moreover, the detection is easier so far, considering the low amount required, the hybridization methods criteria which avoids the production of complex probes like antibodies for proteins and the accessibility of the technologies. The ability of microRNAs to fine tune the gene expression enables these markers to be more sensitive in the pathology follow-up. On the contrary, biomarkers like ctDNA (circulating tumor DNA), which is a promising new biomarker for cancer practice, being strictly linked to genomic mutation analysis, suffer from uncertainty in ongoing follow-up (Nadal et al., 2017). However, some problems still limit the use of microRNAs in personalized medicine. The source of microRNAs has to be managed accordingly and the influence on recovery and final outcome may be substantial, especially for RNA extracted from biofluids. Regarding the detection, the short sequence of microRNAs impedes an easy design of probes, limiting also the discrimination between pri-, pre- and mature forms. Moreover, despite the ease of use and accessibility of qRT-PCR, ddPCR, microarrays and NGS as main detection techniques for nucleic acids, they lack strong sensibility and accuracy, especially at single base resolution. Another key point is the normalization of the signal. In fact, as the analysis is about a relative expression, the choice of a good normalizer is fundamental and challenging (Masè et al., 2017). In addition to these analytical problems, the complex biology of microRNAs increases the obstacles toward a full comprehension of these small non-coding RNAs. As a matter of fact, functional studies with microRNAs suffer from absence of physiological conditions, thus when over-expression studies are performed it should be taken into account that microRNAs generally act with low quantities and more than one on a single target.

Indeed, personalized medicine is going through the use of cmicroRNAs instead of tissue-derivatives. Despite the clear high potential of c-microRNAs in the future personalized medicine, technical difficulties to perform robust and comparable profiling of these small nucleic acids have impeded progress to develop an approved clinical diagnostic assay (Jarry et al., 2014).

The problems come through three different steps in the analysis of c-microRNAs: pre-analytical, analytical and postanalytical phase. Therefore, from where and how c-microRNAs are extracted, how we detect them and how we process the data, still leads to great variability among different studies. Pre-analytical variables are those factors which can affect the composition of the sample to be tested: from patient's conditions variability to sample handling. Firstly, it has to be considered that usually, c-microRNAs are in low titer in biofluids compared to microRNAs in sample tissues. Considering the study of Tewari and colleagues, the concentration of microRNAs in plasma can be counted as from 100 to 9,000 copies per uL or, as shown in another study with ddPCR, even up to 23,000 copies/uL (Miotto et al., 2014). Similar results were found for cardiac injury induced microRNAs (Thompson et al., 2016). Moreover, the lack of knowledge about the secretion and sorting of the microRNAs outside the cells, puts some limits on the patient's condition which would ensure reproducibility on the assays. Another challenge is represented by the contaminant microRNAs. It is known that c-microRNAs come from different cellular sources. Tewari group showed that blood cells are the major contributor to c-microRNAs, therefore variations in blood cells counts and hemolysis can affect the interpretation of c-microRNAs signatures. They studied several oncological biomarkers reported in literature: many of them are highly expressed in blood cells. They demonstrated that this kind of c-microRNAs correlates with blood cell counts and that miR-122, which is not expressed in blood cells, doesn't follow this trend. Moreover, in hemolyzed 
plasma samples, red blood cell-associated microRNAs vary up to 30 -fold compared to non-hemolyzed samples, further proving that c-microRNAs pool is affected by blood cells composition (Pritchard et al., 2012). For these reasons, sample handling and processing become extremely important. Duttagupta and colleagues tried to discriminate between whole blood microRNAs derived from blood cells-“contaminant microRNAs"-and what they called "truly circulating microRNAs". Starting from whole blood samples and collecting different fractions from multiple centrifugation steps (Figure 3) they found that from fraction CS and S1 the content of "contaminant microRNAs" dropped, while the true c-microRNAs content stays more or less unchanged. On top of that, they showed that the variability of expression of marker c-microRNAs among a cohort of males and females decreases after the removal of the cellular contaminants originated from cellular microRNA signatures (Duttagupta et al., 2011). This points out how much the processing of the samples may affect the pool of c-microRNAs. Another study (Cheng et al., 2013) confirmed this variability, reporting that different plasma processing led, for the majority of c-microRNAs, to a variation in their expression levels, mainly due to different platelets and microvesicles content.

From the analytical point of view, it has to be considered that different extraction kits have distinct efficiencies in small RNAs recovery (Monleau et al., 2014). There are several challenges which involve also the detection and quantification of cmicroRNAs. The design of qRT-PCR probes and assays is difficult because of (a) the shortness of microRNAs, (b) their wide range of concentrations, (c) the presence of many precursors and (d) the similarity in sequences. On the post-analytical side, we should mention that most of the detection methods rely on relative quantifications, therefore, an endogenous control is requested. This normalization analysis is needed in order to take into account the biological and technical inter-assay variability. So far, such control for c-microRNAs expression normalization, to be used for every tissue type, treatment and disease stage, has to be discovered yet. The most used in literature are miR-16, snRNA U6 and spiked-in cel-miR-39, but there is no general consensus from the scientific community and a different endogenous control is generally used for different purposes. For instance, among the several transcripts of U6, U6-1 was found to be have high variability and U6-2 was not detectable, in a study on sera from Hepatitis B infected patients and matched controls (Zhu et al., 2012). In two different plasma studies on CRC, miR-16 was found to have quite high stability and little variability between control and case patients (Ng et al., 2009; Huang et al., 2010). In another case, it has been reported, in serum samples from lung cancer patients, miR-16 being inconsistent, choosing to directly normalize the expression levels of target microRNAs to total RNA (Chen et al., 2008). Several authors have concluded that a universal endogenous control is unlikely to be discovered and a suitable reference should be assessed every time considering the different biological conditions of the samples. However, cost and sample requirements needed for the choice of several reference RNAs are not always possible, especially in a clinical or diagnostic setting.

\section{CONCLUSIONS}

As described in the previous paragraphs, microRNAs have some advantages as high specificity, sensitivity, and classification power, which can be exploited for cancer personalized medicine. Furthermore, microRNAs are remarkably stable small molecules shown to be well preserved in FFPE as well as in fresh snap-frozen specimens and in biofluids.

microRNAs affect cancer biology being involved in all the hallmarks of cancer both as tumor suppressor and as onco-miR. They can be extracted from different biological sources and used as biomarkers in order to classify cancerous vs. non-cancerous tissues, distinguish different cancer types and also efficient cancer therapies. Thanks to the sensitive signatures, patterns of microRNAs may be able to follow the progression of cancer, being an important tool in clinical practice. In particular, detection of c-microRNAs, obtained by a non-invasive procedure, seems to be a new promising field with the potential of revolutionizing cancer diagnostics, increasing compliance of patients, ease of use and accessibility to these biomarkers. As a result of a growing use of high-throughput techniques, another emerging field in microRNA diagnostics is represented by SNPs analysis. miRSNP can affect microRNA expression and function, being present on microRNAs sequence, on their target genes or also in genes involved in their biogenesis. They can affect cancer susceptibility, prognosis and response to treatment.

In this review, we reported the main concepts on microRNA cancer personalized medicine. However, some issues have to be

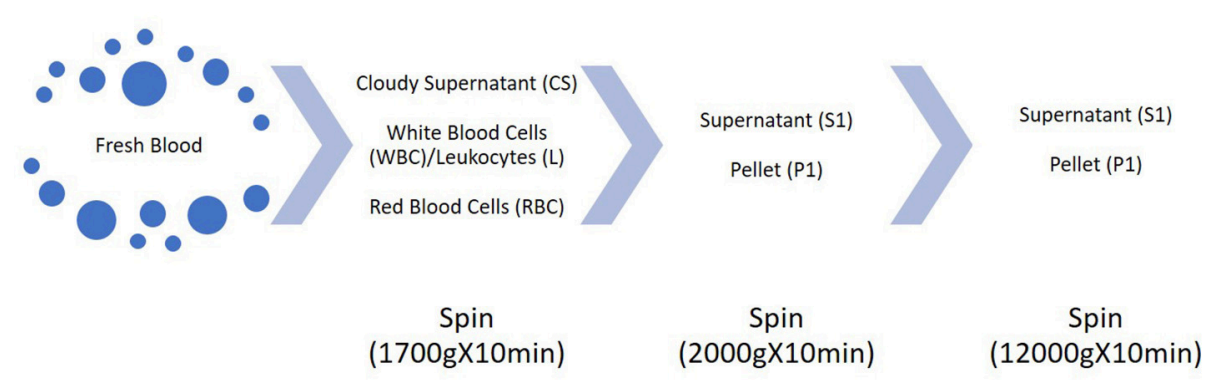

FIGURE 3 | Scheme of the multiple centrifugation steps performed in Duttagupta et al. (2011). 
considered while going through the huge amount of studies on microRNA function and classification capacity.

Despite the advances obtained in the field, many open questions and challenges still remain to be addressed (Table 3). One limitation in microRNAs detection is represented by the closely similar sequences among microRNAs family members, their ancestral RNAs (pre-microRNAs and pri-microRNAs) and isomiRs (Thomas et al., 2010; Chugh and Dittmer, 2012; Zhou et al., 2012). Moreover, there are many methods which can be used to measure microRNAs including qRT-PCR, microarrays, next generation sequencing (NGS), and more recently, digital droplet PCR (ddPCR). These conventional methods have of course their own drawbacks, mainly time-consuming, expensive material and target modification steps for detection. Concerning c-microRNAs, the main limitations are represented by the small amount of RNA and the corresponding microRNAs extracted from biofluids. Indeed, RNA concentration is often under the detection limits of common spectrophotometric devices and this is the reason why for qRT-PCR, it is recommended to use a fixed volume rather than a fixed RNA amount. Furthermore, the right selection of a suitable normalization method to remove technical variations and increase the accuracy of microRNAs quantification is of enormous relevance. The issue of reference genes is especially critical in the quantification of c-microRNAs, due to the extremely low levels in biofluids of common reference genes (U6, miR-16, 5S rRNA, small nucleolar RNAs).

On the other hand, from a biological point of view, microRNAs biogenesis and function must be further explored in order to better understand mechanisms at the basis of their

TABLE 3 | Challenges on microRNA studies from basic microRNA analysis to microRNA functional studies.

microRNA analysis Source of preparation: lack of standardized protocols Discrimination between pri-, pre- and mature forms: difficult to distinguish the different forms of microRNA maturation

Detection techniques: lack of strong sensitivity and sensibility at single-base level

Short sequence for primer design

Quantity in biofluids: the low quantity of microRNAs in biofluids demands high-sensitivity techniques

Normalization methods: the particular nature of microRNAs and their involvement in post-transcriptional regulation makes difficult to find an universal normalizer

microRNA functional studies

High biological complexity: their ability to target multiple mRNAs and the presence of multiple different target sites on a single mRNA creates a complex network of regulation difficult to untangle

Non-physiological conditions: microRNAs generally act as fine-tuners of gene expression, thus, forced over-expression or inhibition in cellular or non-cellular systems are not representative of the reality

Few mechanicistic studies on miRSNP: miRSNP have been studied mainly for their association to cancer risk but only few of these works try to unravel the mechanism underneath the shown effects involvement in cancer. The commonly accepted mechanism of microRNA action and targeting involves the interaction between microRNA 5'-end ("seed region") and mainly the mRNA 3'UTR. However, target sites were found also in the coding sequence (CDS) and in 5' UTR (Lytle et al., 2007; Kloosterman et al., 2016). It has been suggested that this preference could be due to the presence of ribosomes in CDS and translation initiation complexes in $5^{\prime}$ UTR which compete with the RISC complex (Bartel, 2004). Regarding the way of action, microRNAs contribute to gene expression regulation by fine-tuning rather than knocking-down their target mRNA. Thus, microRNAs overexpression performed for luciferase assay or western blot, the "gold standard" techniques to analyze their effect on targets, do not represent the real physiological situation. Although microRNAs exert slight effects on mRNAs, they adopt other strategies to potentiate their regulation. Indeed, one microRNA can simultaneously regulate multiple targets and different microRNAs can have a role as post-transcriptional regulators on the same target. In addition, microRNAs are often involved in feedback loops, thereby potentiating their suppression potential. A complex interplay exists also between transcriptional and posttranscriptional regulators (transcription factors and microRNAs) to orchestrate gene expression and signaling. Moreover, some microRNAs are able to regulate gene expression of their own biogenesis and processing factors, as Dicer (Ristori et al., 2015). Lastly, it is important to take into account the tissue specificity of microRNAs action, thus studies on single tissue-type are to be considered carefully. All these interactions and regulation levels lead to highly complex networks of microRNA/target pathways. For this reason, systems biology approach tries to obtain a more comprehensive understanding of miRNA regulatory structure, combining biological data acquisition and integration, network construction, mathematical modeling and experimental validation.

One important point to mention is that, recently, miRNAtarget interaction knowledge has been enriched by the discovery of long non-coding RNAs (lncRNAs) (Yoon et al., 2014) and circular RNAs (circRNAs) (Hansen et al., 2013; Memczak et al., 2013) and circRNAs which could act as miRNA sponges, reducing their regulatory effect on mRNAs. One hypothesis is that all RNA transcripts containing binding sites for microRNAs can compete specifically for shared microRNAs, acting as competing endogenous RNAs (ceRNAs) (reviewed in Thomson and Dinger, 2016). This concept is extremely important not only for having a complete view of the mechanisms of action of the microRNAs, but also for their biomarker employment.

In the future new more accurate and PCR-free single base sensitive platform are needed. Therefore, a device in which sample-preparation steps (e.g., enzymatic steps for PCR-based amplifications) are removed, would represent an improvement in microRNAs detection and quantification. Some tentative approaches are under study like the integration of a dynamic chemistry for "Single Nucleobase Labeling" with a bead-based platform (Luminex ${ }^{\circledR}$ ) (Venkateswaran et al., 2016), or the use of a power-free microfluidic chip involving a technology based on laminar flow-assisted dendritic amplification (LFDA) (Hasegawa et al., 2017). In the former case the same technology was used to 
detect microRNAs from serum samples (Rissin et al., 2017). On top of that, new methods to avoid normalization of signals are requested, like the use of ratio between the Ct of two different miRNAs (Sharova et al., 2016). As the detection techiques are fundamental, even the source of microRNAs affect the biological outcome. In this sense, exosomes are representing the future of biomarkers from liquid biopsies. More effort in studying this vehicles will help elucidate the mechanism for which microRNAs are realeased in biofluids, thus affecting our way to use them as biomarkers. In addition, the main step forward toward a safe and stable use in clinics of these tools will be the standardization of protocols regarding pre- and post analytical factors. Therefore, a standardized method for isolation of tissues of biofluids as well as preservation of the sample will drastically decrease variability of results, enhancing similarity and robustness of studies in literature. This point is still missing and it is of critical relevance.

In conclusion, microRNAs are fundamental regulator of cell life, linking all its biological functions. Although their analysis has some challenges, the above-mentioned advantages reveal microRNAs as important tools for biomarkers investigation. If

\section{REFERENCES}

Armand-Labit, V., and Pradines, A. (2017). Circulating cell-free microRNAs as clinical cancer biomarkers. Biomol. Concepts 8, 61-81. doi: 10.1515/bmc-2017-0002

Arroyo, J. D., Chevillet, J. R., Kroh, E. M., Ruf, I. K., Pritchard, C. C., Gibson, D. F., et al. (2011). Argonaute2 complexes carry a population of circulating microRNAs independent of vesicles in human plasma. Proc. Natl. Acad. Sci. U.S.A. 108, 5003-5008. doi: 10.1073/pnas. 1019055108

Bartel, D. P. (2004). MicroRNAs: genomics, biogenesis, mechanism, and function. Cell 116, 281-297. doi: 10.1016/S0092-8674(04)00045-5

Bartel, D. P., Abbott, A. L., Alvarez-Saavedra, E., Miska, E. A., Lau, N. C., Bartel, D. P., et al. (2009). MicroRNAs: target recognition and regulatory functions. Cell 136, 215-233. doi: 10.1016/j.cell.2009.01.002

Blenkiron, C., Goldstein, L. D., Thorne, N. P., Spiteri, I., Chin, S.-F., Dunning, M. J., et al. (2007). MicroRNA expression profiling of human breast cancer identifies new markers of tumor subtype. Genome Biol. 8:R214. doi: 10.1186/gb-2007-8-10-r214

Bruhn, O., Drerup, K., Kaehler, M., Haenisch, S., Röder, C., and Cascorbi, I. (2016). Length variants of the ABCB1 $3^{\prime}$-UTR and loss of miRNA binding sites: possible consequences in regulation and pharmacotherapy resistance. Pharmacogenomics 17, 327-340. doi: 10.2217/pgs.15.175

Calatayud, D., Dehlendorff, C., Boisen, M. K., Hasselby, J. P., Schultz, N. A., Werner, J., et al. (2017). Tissue MicroRNA profiles as diagnostic and prognostic biomarkers in patients with resectable pancreatic ductal adenocarcinoma and periampullary cancers. Biomark. Res. 5:8. doi: 10.1186/s40364-017-0087-6

Cammaerts, S., Strazisar, M., De Rijk, P., and Del Favero, J. (2015). Genetic variants in microRNA genes: impact on microRNA expression, function, and disease. Front. Genet. 6:186. doi: 10.3389/fgene.2015.00186

Cao, Y., Zhao, D., Li, P., Wang, L., Qiao, B., Qin, X., et al. (2017). MicroRNA181a-5p impedes IL-17-induced non-small cell lung cancer proliferation and migration through targeting VCAM-1. Cell. Physiol. Biochem. 42, 346-356. doi: $10.1159 / 000477389$

Cappuzzo, F., Sacconi, A., Landi, L., Ludovini, V., Biagioni, F., D’Incecco, A., et al. (2014). MicroRNA signature in metastatic colorectal cancer patients treated with Anti-EGFR monoclonal antibodies. Clin. Colorectal Cancer 13, 37.e4-45.e4. doi: 10.1016/j.clcc.2013.11.006

Cha, D. J., Franklin, J. L., Dou, Y., Liu, Q., Higginbotham, J. N., Demory Beckler, M., et al. (2015). KRAS-dependent sorting of miRNA to exosomes. Elife 4:e07197. doi: 10.7554/eLife.07197 this field will be further pursued, clinicians could be guided by simple tests detecting pattern of microRNAs expression or even single nucleotide variations, making them strongly valid for cancer personalized medicine.

\section{AUTHOR CONTRIBUTIONS}

SD designed the work thinking how it should have been organized, drafted and wrote the manuscript, draw the figures and revised the manuscript critically. MG contributed to the conception and design of the work, supporting the revision for important intellectual content. VDV revised the work critically. MD gave overall intellectual critical support and approved the version to be published. All authors read and approved the final manuscript.

\section{ACKNOWLEDGMENTS}

This work was supported by the EU H2020 MSCA-RISE project miRNA-DisEASY (GA n 690866).

Chan, J. A., Krichevsky, A. M., and Kosik, K. S. (2005). MicroRNA-21 is an antiapoptotic factor in human glioblastoma cells. Cancer Res 65, 6029-6033. doi: 10.1158/0008-5472.CAN-05-0137

Chao, A., Lin, C.-Y., Lee, Y.-S., Tsai, C.-L., Wei, P.-C., Hsueh, S., et al. (2012). Regulation of ovarian cancer progression by microRNA-187 through targeting Disabled homolog-2. Oncogene 31, 764-775. doi: 10.1038/onc.2011.269

Chen, L., Guan, H., Gu, C., Cao, Y., Shao, J., and Wang, F. (2016). miR-383 inhibits hepatocellular carcinoma cell proliferation via targeting APRIL. Tumor Biol.37, 2497-2507. doi: 10.1007/s13277-015-4071-1

Chen, Q., Zhao, X., Zhang, H., Yuan, H., Zhu, M., Sun, Q., et al. (2015). MiR-130b suppresses prostate cancer metastasis through down-regulation of MMP2. Mol Carcinog. 54, 1292-1300. doi: 10.1002/mc.22204

Chen, X., Ba, Y., Ma, L., Cai, X., Yin, Y., Wang, K., et al. (2008). Characterization of microRNAs in serum: a novel class of biomarkers for diagnosis of cancer and other diseases. Cell Res. 18, 997-1006. doi: 10.1038/cr.2008.282

Chen, Z., Yu, T., Cabay, R. J., Jin, Y., Mahjabeen, I., Luan, X., et al. (2017). miR486-3p, miR-139-5p, and miR-21 as biomarkers for the detection of oral tongue squamous cell carcinoma. Biomark. Cancer 9, 1-8. doi: 10.4137/BIC.S40981

Cheng, H. H., Yi, H. S., Kim, Y., Kroh, E. M., Chien, J. W., Eaton, K. D., et al. (2013). Plasma processing conditions substantially influence circulating microRNA biomarker levels. PLoS ONE 8:e64795. doi: 10.1371/journal.pone.0064795

Cheng, Z., Liu, F., Zhang, H., Li, X., Li, Y., Li, J., et al. (2017). miR-135a inhibits tumor metastasis and angiogenesis by targeting FAK pathway. Oncotarget 8 , 31153-31168. doi: 10.18632/oncotarget.16098

Chevillet, J. R., Kang, Q., Ruf, I. K., Briggs, H. A., Vojtech, L. N., Hughes, S. M., et al. (2014). Quantitative and stoichiometric analysis of the microRNA content of exosomes. Proc. Natl. Acad. Sci. U.S.A. 111, 14888-14893. doi: $10.1073 /$ pnas. 1408301111

Chugh, P., and Dittmer, D. P. (2012). Potential pitfalls in microRNA profiling. Wiley Interdiscip. Rev. RNA 3, 601-616. doi: 10.1002/wrna.1120

Cimmino, A., Calin, G. A., Fabbri, M., Iorio, M. V., Ferracin, M., Shimizu, M., et al. (2005). miR-15 and miR-16 induce apoptosis by targeting BCL2. Proc. Natl. Acad. Sci. U.S.A. 102, 13944-13949. doi: 10.1073/pnas.0506654102

Collino, F., Deregibus, M. C., Bruno, S., Sterpone, L., Aghemo, G., Viltono, L., et al. (2010). Microvesicles derived from adult human bone marrow and tissue specific mesenchymal stem cells shuttle selected pattern of miRNAs. PLoS ONE 5:e11803. doi: 10.1371/journal.pone.0011803

Cui, M., Liu, W., Zhang, L., Guo, F., Liu, Y., Chen, F., et al. (2017). Over-expression of miR-21 and lower PTEN Levels in Wilms' Tumor with aggressive behavior. Tohoku J. Exp. Med. 242, 43-52. doi: 10.1620/tjem.242.43 
da Silva Oliveira, K. C., Thomaz Araújo, T. M., Albuquerque, C. I., Barata, G. A., Gigek, C. O., Leal, M. F., et al. (2016). Role of miRNAs and their potential to be useful as diagnostic and prognostic biomarkers in gastric cancer. World J. Gastroenterol. 22, 7951-7962. doi: 10.3748/wjg.v22.i35.7951

Daugaard, I., Venø, M. T., Yan, Y., Kjeldsen, T. E., Lamy, P., Hager, H., et al. (2017). Small RNA sequencing reveals metastasis-related microRNAs in lung adenocarcinoma. Oncotarget 8, 27047-27061. doi: 10.18632/oncotarget.15968

Del Vescovo, V., Cantaloni, C., Cucino, A., Girlando, S., Silvestri, M., Bragantini, E., et al. (2011). miR-205 expression levels in non-small cell lung cancerdo not always distinguish adenocarcinomas from squamous cell carcinomas. Am. J. Surg. Pathol. 35, 268-275. doi: 10.1097/PAS.0b013e3182068171

Del Vescovo, V., and Denti, M. A. (2015). "microRNA and Lung Cancer," in Advances in Experimental Medicine and Biology, eds I. R. COHEN, A. LAJTHA, J. D. LAMBRIS, R. PAOLETTI (Basel: Springer), 153-177.

De Mattos-Arruda, L., Bottai, G., Nuciforo, P. G., Di Tommaso, L., Giovannetti, E., Peg, V., et al. (2015). MicroRNA-21 links epithelial-to-mesenchymal transition and inflammatory signals to confer resistance to neoadjuvant trastuzumab and chemotherapy in HER2-positive breast cancer patients. Oncotarget 6, 37269-37280. doi: 10.18632/oncotarget.5495

Duttagupta, R., Jiang, R., Gollub, J., Getts, R. C., and Jones, K. W. (2011). Impact of cellular miRNAs on circulating miRNA biomarker signatures. PLOS ONE 6:e20769. doi: 10.1371/journal.pone.0020769

Fang, C., Chen, Y.-X., Wu, N.-Y., Yin, J.-Y., Li, X.-P., Huang, H.-S., et al. (2017). MiR-488 inhibits proliferation and cisplatin sensibility in non-small-cell lung cancer (NSCLC) cells by activating the eIF3a-mediated NER signaling pathway. Sci. Rep. 7, 40384. doi: 10.1038/srep40384

Fang, C., Li, X.-P., Gong, W.-J., Wu, N.-Y., Tang, J., Yin, J.-Y., et al. (2016). Age-related common miRNA polymorphism associated with severe toxicity in lung cancer patients treated with platinum-based chemotherapy. Clin. Exp. Pharmacol. Physiol. doi: 10.1111/1440-1681.12704. [Epub ahead of print].

Neviani, P., and Fabbri, M. (2015). Exosomic microRNAs in the tumor microenvironment. Front. Med. 2:47. doi: 10.3389/fmed.2015.00047

Gao, W., Lu, X., Liu, L., Xu, J.i., Feng, D., and Shu, Y. (2012). MiRNA-21. Cancer Biol. Ther. 13, 330-340. doi: 10.4161/cbt.19073

Garcia, A. I., Buisson, M., Bertrand, P., Rimokh, R., Rouleau, E., Lopez, B. S., et al. (2011). Down-regulation of BRCA1 expression by miR-146a and miR-146b$5 \mathrm{p}$ in triple negative sporadic breast cancers. EMBO Mol. Med. 3, 279-290. doi: 10.1002/emmm.201100136

Garcìa-Donas, J., Beuselinck, B., Inglada-Pérez, L., Graña, O., Schöffski, P., Wozniak, A., et al. (2016). Deep sequencing reveals microRNAs predictive of antiangiogenic drug response. JCI Insight 1:e86051. doi: $10.1172 /$ jci.insight. 86051

Garcia-Ortì, L., Cristóbal, I., Cirauqui, C., Guruceaga, E., Marcotegui, N., Calasanz, M. J., et al. (2012). Integration of SNP and mRNA Arrays with MicroRNA profiling reveals that MiR-370 is upregulated and targets NF1 in acute myeloid leukemia. PLoS ONE 7:e47717. doi: 10.1371/journal.pone.0047717

Geng, J.-Q., Wang, X.-C., Li, L.-F., Zhao, J., Wu, S., Yu, G.-P., et al. (2016). MicroRNA-related single-nucleotide polymorphism of XPO5 is strongly correlated with the prognosis and chemotherapy response in advanced non-small-cell lung cancer patients. Tumor Biol. 37, 2257-2265. doi: 10.1007/s13277-015-3980-3

Go, H., Jang, J.-Y., Kim, P.-J., Kim, Y.-G., Nam, S. J., Paik, J. H., et al. (2015). MicroRNA-21 plays an oncogenic role by targeting FOXO1 and activating the PI3K/AKT pathway in diffuse large B-cell lymphoma. Oncotarget 6, 15035-15049. doi: 10.18632/oncotarget.3729

Godnic, I., Zorc, M., Jevsinek Skok, D., Calin, G. A., Horvat, S., Dovc, P., et al. (2013). Genome-wide and species-wide in silico screening for intragenic micrornas in human, mouse and chicken. PLoS ONE 8:e65165. doi: 10.1371/journal.pone.0065165

Gong, J., Tong, Y., Zhang, H.-M., Wang, K., Hu, T., Shan, G., et al. (2012). Genome-wide identification of SNPs in microRNA genes and the SNP effects on microRNA target binding and biogenesis. Hum. Mutat. 33, 254-263. doi: 10.1002/humu.21641

Grundhoff, A., and Sullivan, C. S. (2011). Virus-encoded microRNAs. Virology 411, 325-343. doi: 10.1016/j.virol.2011.01.002

Gu, D., Jiang, M., Mei, Z., Dai, J., Dai, C., Fang, C., et al. (2017). microRNA7 impairs autophagy-derived pools of glucose to suppress pancreatic cancer progression. Cancer Lett. 400, 69-78. doi: 10.1016/j.canlet.2017.04.020
Guzman, N., Agarwal, K., Asthagiri, D., Yu, L., Saji, M., Ringel, M. D., et al. (2015). Breast cancer-specific miR signature unique to extracellular vesicles includes "microRNA-like" tRNA fragments. Mol. Cancer Res. 13, 891-901. doi: 10.1158/1541-7786.MCR-14-0533

Hanahan, D., and Weinberg, R. (2011). Hallmarks of cancer: the next generation. Cell 144, 646-674. doi: 10.1016/j.cell.2011.02.013

Hansen, T. B., Jensen, T. I., Clausen, B. H., Bramsen, J. B., Finsen, B., Damgaard, C. K., et al. (2013). Natural RNA circles function as efficient microRNA sponges. Nature 495, 384-388. doi: 10.1038/nature11993

Hasegawa, K., Negishi, R., Matsumoto, M., Yohda, M., Hosokawa, K., and Maeda, M. (2017). Specificity of MicroRNA Detection on a power-free microfluidic chip with laminar flow-assisted dendritic amplification. Anal. Sci. 33, 171-177. doi: 10.2116/analsci.33.171

He, Q., Cai, L., Shuai, L., Li, D., Wang, C., Liu, Y., et al. (2013). Ars2 is overexpressed in human cholangiocarcinomas and its depletion increases PTEN and PDCD4 by decreasing microRNA-21. Mol. Carcinog. 52, 286-296. doi: $10.1002 / \mathrm{mc} .21859$

He, Z., Cen, D., Luo, X., Li, D., Li, P., Liang, L., et al. (2013). Downregulation of miR-383 promotes glioma cell invasion by targeting insulin-like growth factor 1 receptor. Med. Oncol. 30:557. doi: 10.1007/s12032-013-0557-0

Hezova, R., Kovarikova, A., Srovnal, J., Zemanova, M., Harustiak, T., Ehrmann, J., et al. (2015). Diagnostic and prognostic potential of miR-21, miR-29c, miR-148 and miR-203 in adenocarcinoma and squamous cell carcinoma of esophagus. Diagn. Pathol. 10:42. doi: 10.1186/s13000-015-0280-6

Hoffman, A. E., Zheng, T., Yi, C., Leaderer, D., Weidhaas, J., Slack, F. et al. (2009). microRNA miR-196a-2 and breast cancer: a genetic and epigenetic association study and functional analysis. Cancer Res. 69, 5970-5977. doi: 10.1158/0008-5472.CAN-09-0236

Hsu, Y.-L., Hung, J.-Y., Chang, W.-A., Lin, Y.-S., Pan, Y.-C., Tsai, P.H., et al. (2017). Hypoxic lung cancer-secreted exosomal miR-23a increased angiogenesis and vascular permeability by targeting prolyl hydroxylase and tight junction protein ZO-1. Oncogene 36, 4929-4942. doi: 10.1038/onc.2017.105

Hu, Z., Chen, J., Tian, T., Zhou, X., Gu, H., Xu, L., et al. (2008). Genetic variants of miRNA sequences and non-small cell lung cancer survival. J. Clin. Invest. 118, 2600-2608. doi: 10.1172/JCI34934

Huang, H., Tian, H., Duan, Z., Cao, Y., Zhang, X.-S., and Sun, F. (2014). microRNA-383 impairs phosphorylation of H2AX by targeting PNUTS and inducing cell cycle arrest in testicular embryonal carcinoma cells. Cell. Signal. 26, 903-911. doi: 10.1016/j.cellsig.2014.01.016

Huang, X., and Lu, S. (2017). MicroR-545 mediates colorectal cancer cells proliferation through up-regulating epidermal growth factor receptor expression in HOTAIR long non-coding RNA dependent. Mol. Cell. Biochem. 431, 45-54. doi: 10.1007/s11010-017-2974-4

Huang, Z., Huang, D., Ni, S., Peng, Z., Sheng, W., and Du, X. (2010). Plasma microRNAs are promising novel biomarkers for early detection of colorectal cancer. Int. J. Cancer 127, 118-126. doi: 10.1002/ijc.25007

Hwang, J.-H., Voortman, J., Giovannetti, E., Steinberg, S. M., Leon, L. G., Kim, Y.-T., et al. (2010). Identification of MicroRNA-21 as a biomarker for chemoresistance and clinical outcome following adjuvant therapy in resectable pancreatic cancer. PLoS ONE 5:e10630. doi: 10.1371/journal.pone.0010630

Igarashi, H., Kurihara, H., Mitsuhashi, K., Ito, M., Okuda, H., Kanno, S., et al. (2015). Association of MicroRNA-31-5p with clinical efficacy of anti-EGFR therapy in patients with metastatic colorectal cancer. Ann. Surg. Oncol. 22, 2640-2648. doi: 10.1245/s10434-014-4264-7

Iorio, M. V., Ferracin, M., Liu, C.-G., Veronese, A., Spizzo, R., Sabbioni, S., et al. (2005). MicroRNA gene expression deregulation in human breast cancer. Cancer Res. 65, 7065-7070. doi: 10.1158/0008-5472.CAN-05-1783

Iorio, M. V., Visone, R., Di Leva, G., Donati, V., Petrocca, F., Casalini, P., et al. (2007). MicroRNA signatures in human ovarian cancer. Cancer Res. 67, 8699-8707. doi: 10.1158/0008-5472.CAN-07-1936

Ipsaro, J. J., and Joshua-Tor, L. (2015). From guide to target: molecular insights into eukaryotic RNA-interference machinery. Nat. Struct. Mol. Biol. 22, 20-28. doi: 10.1038/nsmb.2931

Janas, T., Janas, M. M., SapońK., and Janas, T. (2015). Mechanisms of RNA loading into exosomes. FEBS Lett. 589, 1391-1398. doi: 10.1016/j.febslet.2015.04.036

Jarry, J., Schadendorf, D., Greenwood, C., Spatz, A., and van Kempen, L. C. (2014). The validity of circulating microRNAs in oncology: five years of challenges 
and contradictions. Mol. Oncol. 8, 819-829. doi: 10.1016/j.molonc.2014. 02.009

Jiang, Y., Chen, J., Wu, J., Hu, Z., Qin, Z., Liu, X., et al. (2013). Evaluation of genetic variants in microRNA biosynthesis genes and risk of breast cancer in Chinese women. Int. J. Cancer 133, 2216-2224. doi: 10.1002/ijc.28237

Jones-Rhoades, M. W., Bartel, D. P., and Bartel, B. (2006). MicroRNAS and their regulatory roles in plants. Annu. Rev. Plant Biol. 57, 19-53. doi: 10.1146/annurev.arplant.57.032905.105218

Kapodistrias, N., Mavridis, K., Batistatou, A., Gogou, P., Karavasilis, V., Sainis, I., et al. (2016). Assessing the clinical value of microRNAs in formalin-fixed paraffin-embedded liposarcoma tissues: overexpressed miR-155 is an indicator of poor prognosis. Oncotarget 8, 6896-6913. doi: 10.18632/oncotarget.14320

Ke, J., Tian, J., Li, J., Gong, Y., Yang, Y., Zhu, Y., et al. (2017). Identification of a functional polymorphism affecting microRNA binding in the susceptibility locus 1q25.3 for colorectal cancer. Mol. Carcinog. 56, 2014-2021. doi: $10.1002 / \mathrm{mc} .22649$

Khorrami, S., Zavaran Hosseini, A., Mowla, S. J., Soleimani, M., Rakhshani, N., and Malekzadeh, R. (2017). MicroRNA-146a induces immune suppression and drug-resistant colorectal cancer cells. Tumor Biol. 39:101042831769836. doi: $10.1177 / 1010428317698365$

Kijima, T., Hazama, S., Tsunedomi, R., Tanaka, H., Takenouchi, H., Kanekiyo, S., et al. (2016). MicroRNA-6826 and-6875 in plasma are valuable non-invasive biomarkers that predict the efficacy of vaccine treatment against metastatic colorectal cancer. Oncol. Rep. 37, 23-30. doi: 10.3892/or.2016.5267

Kloosterman, W. P., Wienholds, E., Ketting, R. F., and Plasterk, R. H. A. (2016). Substrate requirements for let-7 function in the developing zebrafish embryo. Nucleic Acids Res. 44, 5993-5993. doi: 10.1093/nar/gkw173

Koppers-Lalic, D., Hackenberg, M., Bijnsdorp, I. V., van Eijndhoven, M. A. J., Sadek, P., Sie, D., et al. (2014). Nontemplated nucleotide additions distinguish the small RNA composition in cells from exosomes. Cell Rep. 8, 1649-1658. doi: 10.1016/j.celrep.2014.08.027

Kosaka, N., Iguchi, H., Yoshioka, Y., Takeshita, F., Matsuki, Y., and Ochiya, T. (2010). Secretory mechanisms and intercellular transfer of microRNAs in living cells. J. Biol. Chem. 285, 17442-17452. doi: 10.1074/jbc.M110.107821

Kumarswamy, R., Mudduluru, G., Ceppi, P., Muppala, S., Kozlowski, M., Niklinski, J., et al. (2012). MicroRNA-30a inhibits epithelial-to-mesenchymal transition by targeting Snail and is downregulated in non-small cell lung cancer. Int. J. Cancer 130, 2044-2053. doi: 10.1002/ijc.26218

Lebanony, D., Benjamin, H., Gilad, S., Ezagouri, M., Dov, A., Ashkenazi, K., et al. (2009). Diagnostic assay based on hsa-miR-205 expression distinguishes squamous from nonsquamous non-small-cell lung carcinoma. J. Clin. Oncol. 27, 2030-2037. doi: 10.1200/JCO.2008.19.4134

Lee, A.-R., Park, J., Jung, K. J., Jee, S. H., and Kim-Yoon, S. (2016). Genetic variation rs7930 in the miR-4273-5p target site is associated with a risk of colorectal cancer. Onco. Targets. Ther. 9, 6885-6895. doi: $10.2147 / O T T . S 108787$

Lee, R. C., Feinbaum, R. L., Ambros, V., Arasu, P., Ruvkun, G., Staden, R., et al. (1993). The C. elegans heterochronic gene lin-4 encodes small RNAs with antisense complementarity to lin-14. Cell 75, 843-854. doi: 10.1016/0092-8674(93)90529-Y

Lee, Y., Ahn, C., Han, J., Choi, H., Kim, J., Yim, J., et al. (2003). The nuclear RNase III Drosha initiates microRNA processing. Nature 425, 415-419. doi: 10.1038/nature01957

Leidner, R. S., Ravi, L., Leahy, P., Chen, Y., Bednarchik, B., Streppel, M., et al. (2012). The microRNAs, MiR-31 and MiR-375, as candidate markers in Barrett's esophageal carcinogenesis. Genes, Chromosom. Cancer 51, 473-479. doi: $10.1002 /$ gcc. 21934

Li, B., Ge, L., Li, M., Wang, L., and Li, Z. (2016). miR-448 suppresses proliferation and invasion by regulating IGF1R in colorectal cancer cells. Am. J. Transl. Res. 8, 3013-3022.

Li, J., Lei, K., Wu, Z., Li, W., Liu, G., Liu, J., et al. (2014a). Network-based identification of microRNAs as potential pharmacogenomic biomarkers for anticancer drugs. Oncotarget 7, 45584-45596. doi: 10.18632/oncotarget.10052

Li, J., Li, X., Ren, S., Chen, X., Zhang, Y., Zhou, F., et al. (2014b). miR-200c overexpression is associated with better efficacy of EGFR-TKIs in non-small cell lung cancer patients with EGFR wild-type. Oncotarget 5, 7902-7916. doi: $10.18632 /$ oncotarget.2302
Li, K. K.-W., Pang, J. C.-S., Lau, K.-M., Zhou, L., Mao, Y., Wang, Y., et al. (2013). MiR-383 is downregulated in medulloblastoma and targets peroxiredoxin 3 (PRDX3). Brain Pathol. 23, 413-425. doi: 10.1111/bpa.12014

Li, L., and Luo, Z. (2017). Dysregulated miR-27a-3p promotes nasopharyngeal carcinoma cell proliferation and migration by targeting Mapk10. Oncol. Rep. 37, 2679-2687. doi: 10.3892/or.2017.5544

Li, Q.-Q., Chen, Z.-Q., Cao, X.-X., Xu, J.-D., Xu, J.-W., Chen, Y.-Y., et al. (2011). Involvement of NF-кB/miR-448 regulatory feedback loop in chemotherapyinduced epithelial?mesenchymal transition of breast cancer cells. Cell Death Differ. 18, 16-25. doi: 10.1038/cdd.2010.103

Li, S.-J., Liu, H.-L., Tang, S.-L., Li, X.-J., and Wang, X.-Y. (2017). MicroRNA150 regulates glycolysis by targeting von Hippel-Lindau in glioma cells. Am. J. Transl. Res. 9, 1058-1066.

Lian, J., Tian, H., Liu, L., Zhang, X.-S., Li, W.-Q., Deng, Y.-M., et al. (2010). Downregulation of microRNA-383 is associated with male infertility and promotes testicular embryonal carcinoma cell proliferation by targeting IRF1. Cell Death Dis. 1:e94. doi: 10.1038/cddis.2010.70

Lin, M., Gu, J., Eng, C., Ellis, L. M., Hildebrandt, M. A., Lin, J., et al. (2012). Genetic polymorphisms in MicroRNA-related genes as predictors of clinical outcomes in colorectal adenocarcinoma patients. Clin. Cancer Res. 18, 3982-3991. doi: 10.1158/1078-0432.CCR-11-2951

Liu, C., Zhang, Y., Chen, H., Jiang, L., and Xiao, D. (2016). Function analysis of rs9589207 polymorphism in miR-92a in gastric cancer. Tumor Biol. 37, 4439-4444. doi: 10.1007/s13277-015-4288-z

Liu, H., Zhou, Y., Liu, Q., Xiao, G., Wang, B., Li, W., et al. (2017). Association of miR-608 rs4919510 polymorphism and cancer risk: a meta-analysis based on 13,664 subjects. Oncotarget 8, 37023-37031. doi: 10.18632/oncotarget.9509

Liu, Y., Chai, Y., Zhang, J., and Tang, J. (2016). A function variant at miR-501 alters susceptibility to hepatocellular carcinoma in a chinese han population. Cell. Physiol. Biochem. 38, 2500-2508. doi: 10.1159/000445600

Liu, Y., Liu, R., Yang, F., Cheng, R., Chen, X., Cui, S., et al. (2017). miR-19a promotes colorectal cancer proliferation and migration by targeting TIA1. Mol. Cancer 16:53. doi: 10.1186/s12943-017-0625-8

Lopez-Lopez, E., Gutierrez-Camino, A., Astigarraga, I., Navajas, A., EchebarriaBarona, A., Garcia-Miguel, P., et al. (2016). Vincristine pharmacokinetics pathway and neurotoxicity during early phases of treatment in pediatric acute lymphoblastic leukemia. Pharmacogenomics 17, 731-741. doi: 10.2217/pgs-2016-0001

Lopez-Lopez, E., Gutiérrez-Camino, Á., Piñán, M. Á., Sánchez-Toledo, J., Uriz, J. J., Ballesteros, J., et al. (2014). Pharmacogenetics of microRNAs and microRNAs biogenesis machinery in pediatric acute lymphoblastic leukemia. PLoS ONE 9:e91261. doi: 10.1371/journal.pone.0091261

Lu, J., Getz, G., Miska, E. A., Alvarez-Saavedra, E., Lamb, J., Peck, D., et al. (2005). microRNA expression profiles classify human cancers. Nature $435,834-838$. doi: 10.1038/nature03702

Lu, M., Kong, X., Wang, H., Huang, G., Ye, C., and He, Z. (2017). A novel microRNAs expression signature for hepatocellular carcinoma diagnosis and prognosis. Oncotarget 8, 8775-8784. doi: 10.18632/oncotarget.14452

Lv, Y., Lei, Y., Hu, Y., Ding, W., Zhang, C., and Fang, C. (2015). miR-448 negatively regulates ovarian cancer cell growth and metastasis by targeting CXCL12. Clin. Transl. Oncol. 17, 903-909. doi: 10.1007/s12094-015-1325-8

Lytle, J. R., Yario, T. A., and Steitz, J. A. (2007). Target mRNAs are repressed as efficiently by microRNA-binding sites in the 5' UTR as in the 3' UTR. Proc. Natl. Acad. Sci. U.S.A. 104, 9667-9672. doi: 10.1073/pnas.0703820104

Makarova, J. A., Shkurnikov, M. U., Wicklein, D., Lange, T., Samatov, T. R., Turchinovich, A. A., et al. (2016). Intracellular and extracellular microRNA: an update on localization and biological role. Prog. Histochem. Cytochem. 51, 33-49. doi: 10.1016/j.proghi.2016.06.001

Markou, A., Tsaroucha, E. G., Kaklamanis, L., Fotinou, M., Georgoulias, V., and Lianidou, E. S. (2008). Prognostic value of mature MicroRNA21 and MicroRNA-205 overexpression in non-small cell lung cancer by quantitative real-time RT-PCR. Clin. Chem. 54, 1696-1704. doi: 10.1373/clinchem.2007.101741

Masè, M., Grasso, M., Avogaro, L., D’Amato, E., Tessarolo, F., Graffigna, A., et al. (2017). Selection of reference genes is critical for miRNA expression analysis in human cardiac tissue. A focus on atrial fibrillation. Sci. Rep. 7:41127. doi: $10.1038 /$ srep41127 
Matsuzaki, J., and Ochiya, T. (2017). Circulating microRNAs and extracellular vesicles as potential cancer biomarkers: a systematic review. Int. J. Clin. Oncol. 22, 413-420. doi: 10.1007/s10147-017-1104-3

Memczak, S., Jens, M., Elefsinioti, A., Torti, F., Krueger, J., Rybak, A., et al. (2013). Circular RNAs are a large class of animal RNAs with regulatory potency. Nature 495, 333-338. doi: 10.1038/nature11928

Meng, F., Henson, R., Wehbe-Janek, H., Ghoshal, K., Jacob, S. T., and Patel, T. (2007). MicroRNA-21 regulates expression of the PTEN tumor suppressor gene in human hepatocellular cancer. Gastroenterology 133, 647-658. doi: 10.1053/j.gastro.2007.05.022

Meshkat, M., Tanha, H. M., Naeini, M. M., Ghaedi, K., Sanati, M. H., Meshkat, M., et al. (2016). Functional SNP in stem of mir-146a affects Her2 status and breast cancer survival. Cancer Biomarkers 17, 213-222. doi: 10.3233/CBM-160633

Mi, Y., Zhang, D., Jiang, W., Weng, J., Zhou, C., Huang, K., et al. (2017). miR-181a$5 p$ promotes the progression of gastric cancer via RASSF6-mediated MAPK signalling activation. Cancer Lett. 389, 11-22. doi: 10.1016/j.canlet.2016.12.033

Min, P., Li, W., Zeng, D., Ma, Y., Xu, D., Zheng, W., et al. (2017). A single nucleotide variant in microRNA-1269a promotes the occurrence and process of hepatocellular carcinoma by targeting to oncogenes SPATS2L and LRP6. Bull. Cancer 104, 311-320. doi: 10.1016/j.bulcan.2016.11.021

Miotto, E., Saccenti, E., Lupini, L., Callegari, E., Negrini, M., and Ferracin, M. (2014). Quantification of Circulating miRNAs by Droplet Digital PCR: comparison of EvaGreen- and TaqMan-Based Chemistries. Cancer Epidemiol. Prev. Biomarkers 23. 2638-2642. doi: 10.1158/1055-9965

Mitchell, P. S., Parkin, R. K., Kroh, E. M., Fritz, B. R., Wyman, S. K., PogosovaAgadjanyan, E. L., et al. (2008). Circulating microRNAs as stable blood-based markers for cancer detection. Proc. Natl. Acad. Sci. U.S.A. 105, 10513-10518. doi: $10.1073 /$ pnas. 0804549105

Mlcochova, J., Faltejskova-Vychytilova, P., Ferracin, M., Zagatti, B., Radova, L., Svoboda, M., et al. (2015). MicroRNA expression profiling identifies miR$31-5 p / 3 p$ as associated with time to progression in wild-type RAS metastatic colorectal cancer treated with cetuximab. Oncotarget 6, 38695-38704. doi: 10.18632/oncotarget.5735

Mohammadi, A., Mansoori, B., and Baradaran, B. (2016). The role of microRNAs in colorectal cancer. Biomed. Pharmacother. 84, 705-713. doi: 10.1016/j.biopha.2016.09.099

Molasy, M., Walczak, A., Szaflik, J., Szaflik, J. P., and Majsterek, I. (2016). MicroRNAs in glaucoma and neurodegenerative diseases. J. Hum. Genet. 62, 105-112. doi: 10.1038/jhg.2016.91

Monleau, M., Bonnel, S., Gostan, T., Blanchard, D., Courgnaud, V., Lecellier, C.-H., et al. (2014). Comparison of different extraction techniques to profile microRNAs from human sera and peripheral blood mononuclear cells. $B M C$ Genomics 15:395. doi: 10.1186/1471-2164-15-395

Montes-Moreno, S., Martinez, N., Sanchez-Espiridión, B., Díaz Uriarte, R., Rodriguez, M. E., Saez, A., et al. (2011). miRNA expression in diffuse large B-cell lymphoma treated with chemoimmunotherapy. Blood 118. 1034-1040. doi: 10.1182/blood-2010-11-321554

Mosakhani, N., Lahti, L., Borze, I., Karjalainen-Lindsberg, M.-L., Sundström, J., Ristamäki, R., et al. (2012). MicroRNA profiling predicts survival in anti-EGFR treated chemorefractory metastatic colorectal cancer patients with wild-type KRAS and BRAF. Cancer Genet. 205, 545-551. doi: 10.1016/j.cancergen.2012.08.003

Mott, J. L., Kobayashi, S., Bronk, S. F., and Gores, G. J. (2007). mir-29 regulates Mcl-1 protein expression and apoptosis. Oncogene 26, 6133-6140. doi: 10.1038/sj.onc.1210436

Mullany, L. E., Herrick, J. S., Wolff, R. K., Buas, M. F., and Slattery, M. L. (2016). Impact of polymorphisms in microRNA biogenesis genes on colon cancer risk and microRNA expression levels: a population-based, case-control study. $B M C$ Med. Genomics 9:21. doi: 10.1186/s12920-016-0181-x

Nadal, C., Winder, T., Gerger, A., and Tougeron, D. (2017). Future perspectives of circulating tumor DNA in colorectal cancer. Tumor Biol. 39:101042831770574. doi: $10.1177 / 1010428317705749$

Nakka, M., Allen-Rhoades, W., Li, Y., Kelly, A. J., Shen, J., Taylor, A. M., et al. (2017). Biomarker significance of plasma and tumor miR-21, miR-221, and miR-106a in osteosarcoma. Oncotarget doi: 10.18632/oncotarget.18236

Namkung, J., Kwon, W., Choi, Y., Yi, S. G., Han, S., Kang, M. J., et al. (2016). Molecular subtypes of pancreatic cancer based on miRNA expression profiles have independent prognostic value. J. Gastroenterol. Hepatol. 31, 1160-1167. doi: 10.1111 /jgh. 13253

Neault, M., Mallette, F. A., and Richard, S. (2016). miR-137 modulates a tumor suppressor network-inducing senescence in pancreatic cancer cells. Cell Rep. 14, 1966-1978. doi: 10.1016/j.celrep.2016.01.068

Ng, E. K. O., Chong, W. W. S., Jin, H., Lam, E. K. Y., Shin, V. Y., Yu, J., et al. (2009). Differential expression of microRNAs in plasma of patients with colorectal cancer: a potential marker for colorectal cancer screening. Gut 58, 1375-1381. doi: $10.1136 /$ gut.2008.167817

Nishida, N., Arizumi, T., Hagiwara, S., Ida, H., Sakurai, T., and Kudo, M. (2017). MicroRNAs for the prediction of early response to sorafenib treatment in human hepatocellular carcinoma. Liver Cancer 6, 113-125. doi: 10.1159/000449475

Ochoa, A. E., Choi, W., Su, X., Siefker-Radtke, A., Czerniak, B., Dinney, C., et al. (2016). Specific micro-RNA expression patterns distinguish the basal and luminal subtypes of muscle-invasive bladder cancer. Oncotarget 7 , 80164-80174. doi: 10.18632/oncotarget.13284

Parafioriti, A., Bason, C., Armiraglio, E., Calciano, L., Daolio, P. A., Berardocco, M., et al. (2016). Ewing's sarcoma: an analysis of mirna expression profiles and target genes in paraffin-embedded primary tumor tissue. Int. J. Mol. Sci. 17, 656. doi: $10.3390 /$ ijms 17050656

Pardini, B., Rosa, F., Naccarati, A., Vymetalkova, V., Ye, Y., Wu, X., et al. (2015). Polymorphisms in microRNA genes as predictors of clinical outcomes in colorectal cancer patients. Carcinogenesis 36, 82-86. doi: 10.1093/carcin/bgu224

Parkin, B., Ouillette, P., Wang, Y., Liu, Y., Wright, W., Roulston, D., et al. (2010). NF1 inactivation in adult acute myelogenous leukemia. Clin. Cancer Res. 16, 4135-4147. doi: 10.1158/1078-0432.CCR-09-2639

Patnaik, S., Mallick, R., Kannisto, E., Sharma, R., Bshara, W., Yendamuri, S., et al (2015). MiR-205 and MiR-375 microRNA assays to distinguish squamous cell carcinoma from adenocarcinoma in lung cancer biopsies. J. Thorac. Oncol. 10, 446-453. doi: 10.1097/JTO.0000000000000423

Paydas, S., Acikalin, A., Ergin, M., Celik, H., Yavuz, B., and Tanriverdi, K. (2016). Micro-RNA (miRNA) profile in Hodgkin lymphoma: association between clinical and pathological variables. Med. Oncol. 33:34. doi: 10.1007/s12032-016-0749-5

Peng, J., Liu, H.-Z., Zhong, J., Deng, Z.-F., Tie, C.-R., Rao, Q., et al. (2016). MicroRNA-187 is an independent prognostic factor in lung cancer and promotes lung cancer cell invasion via targeting of PTRF. Oncol. Rep. 36, 2609-2618. doi: 10.3892/or.2016.5083

Preis, M., Gardner, T. B., Gordon, S. R., Pipas, J. M., Mackenzie, T. A., Klein, E. E., et al. (2011). MicroRNA-10b expression correlates with response to neoadjuvant therapy and survival in pancreatic ductal adenocarcinoma. Clin. Cancer Res. 17, 5812-5821. doi: 10.1158/1078-0432.CCR-11-0695

Pritchard, C. C., Kroh, E., Wood, B., Arroyo, J. D., Dougherty, K. J., Miyaji, M. M., et al. (2012). Blood cell origin of circulating microRNAs: a cautionary note for cancer biomarker studies. Cancer Prev. Res. (Phila). 5, 492-497. doi: 10.1158/1940-6207.CAPR-11-0370

Ramalho-Carvalho, J., Graça, I., Gomez, A., Oliveira, J., Henrique, R., Esteller, M., et al. (2017). Downregulation of miR-130b 301b cluster is mediated by aberrant promoter methylation and impairs cellular senescence in prostate cancer. J. Hematol. Oncol. 10:43. doi: 10.1186/s13045-017-0415-1

Rapa, I., Votta, A., Felice, B., Righi, L., Giorcelli, J., Scarpa, A., et al. (2015). Identification of MicroRNAs differentially expressed in lung carcinoid subtypes and progression. Neuroendocrinology 101, 246-255. doi: 10.1159/ 000381454

Raponi, M., Dossey, L., Jatkoe, T., Wu, X., Chen, G., Fan, H., et al. (2009). MicroRNA classifiers for predicting prognosis of squamous cell lung cancer. Cancer Res. 69, 5776-5783. doi: 10.1158/0008-5472.CAN-09-0587

Reddy, P. H., Tonk, S., Kumar, S., Vijayan, M., Kandimalla, R., Kuruva, C. S., et al. (2016). A critical evaluation of neuroprotective and neurodegenerative MicroRNAs in Alzheimer's disease. Biochem. Biophys. Res. Commun. 483, 1156-1165. doi: 10.1016/j.bbrc.2016.08.067

Revathidevi, S., Sudesh, R., Vaishnavi, V., Kaliyanasundaram, M., MaryHelen, K. G., Sukanya, G., et al. (2016). Screening for the 3'UTR polymorphism of the PXR gene in South Indian breast cancer patients and its potential role in pharmacogenomics. Asian Pac. J. Cancer Prev. 17, 3971-3977. 
Rissin, D. M., López-Longarela, B., Pernagallo, S., Ilyine, H., Vliegenthart, A. D. B., Dear, J. W., et al. (2017). Polymerase-free measurement of microRNA122 with single base specificity using single molecule arrays: detection of drug-induced liver injury. PLoS ONE 12:e0179669. doi: 10.1371/journal.pone. 0179669

Ristori, E., Lopez-Ramirez, M., Narayanan, A., Hill-Teran, G., Moro, A., Calvo, C.-F., et al. (2015). A Dicer-miR-107 interaction regulates biogenesis of specific miRNAs crucial for neurogenesis. Dev. Cell 32, 546-560. doi: 10.1016/j.devcel.2014.12.013

Rosenfeld, N., Aharonov, R., Meiri, E., Rosenwald, S., Spector, Y., Zepeniuk, M., et al. (2008). MicroRNAs accurately identify cancer tissue origin. Nat. Biotechnol. 26, 462-469. doi: 10.1038/nbt1392

Rotunno, M., Zhao, Y., Bergen, A. W., Koshiol, J., Burdette, L., Rubagotti, M., et al. (2010). Inherited polymorphisms in the RNA-mediated interference machinery affect microRNA expression and lung cancer survival. Br. J. Cancer 103, 1870-1874. doi: 10.1038/si.bjc.6605976

Rukov, J. L., Vinther, J., and Shomron, N. (2011). Pharmacogenomics genes show varying perceptibility to microRNA regulation. Pharmacogenet. Genomics 21, 251-262. doi: 10.1097/FPC.0b013e3283438865

Rusca, N., and Monticelli, S. (2011). MiR-146a in Immunity and Disease. Mol. Biol. Int. 2011:437301. doi: 10.4061/2011/437301

Schetter, A. J., Leung, S. Y., Sohn, J. J., Zanetti, K. A., Bowman, E. D., Yanaihara, N., et al. (2008). MicroRNA expression profiles associated with prognosis and therapeutic outcome in colon adenocarcinoma. JAMA 299, 425-436. doi: 10.1001/jama.299.4.425

Schetter, A. J., Nguyen, G. H., Bowman, E. D., Mathé, E. A., Yuen, S. T., Hawkes, J. E., et al. (2009). Association of inflammation-related and microRNA gene expression with cancer-specific mortality of colon adenocarcinoma. Clin. Cancer Res. 15, 5878-5887. doi: 10.1158/1078-0432.CCR-09-0627

Schweiger, M. R., Kerick, M., Timmermann, B., and Isau, M. (2011). The power of NGS technologies to delineate the genome organization in cancer: from mutations to structural variations and epigenetic alterations. Cancer Metastasis Rev. 30, 199-210. doi: 10.1007/s10555-011-9278-Z

Shan, C., Fei, F., Li, F., Zhuang, B., Zheng, Y., Wan, Y., et al. (2017). miR-448 is a novel prognostic factor of lung squamous cell carcinoma and regulates cells growth and metastasis by targeting DCLK1. Biomed. Pharmacother. 89, 1227-1234. doi: 10.1016/j.biopha.2017.02.017

Shang, Y., Zang, A., Li, J., Jia, Y., Li, X., Zhang, L., et al. (2016). MicroRNA-383 is a tumor suppressor and potential prognostic biomarker in human non-small cell lung caner. Biomed. Pharmacother. 83, 1175-1181. doi: 10.1016/j.biopha.2016.08.006

Sharova, E., Grassi, A., Marcer, A., Ruggero, K., Pinto, F., Bassi, P., et al. (2016). A circulating miRNA assay as a first-line test for prostate cancer screening. Br. J. Cancer 114, 1362-1366. doi: 10.1038/bjc.2016.151

Shi, L., Cheng, Z., Zhang, J., Li, R., Zhao, P., Fu, Z., et al. (2008). hsa-mir-181a and hsa-mir-181b function as tumor suppressors in human glioma cells. Brain Res. 1236, 185-193. doi: 10.1016/j.brainres.2008.07.085

Si, M.-L., Zhu, S., Wu, H., Lu, Z., Wu, F., and Mo, Y.-Y. (2007). miR-21-mediated tumor growth. Oncogene 26, 2799-2803. doi: 10.1038/sj.onc.1210083

Sibin, M. K., Harshitha, S. M., Narasingarao, K. V. L., Dhananjaya, I. B., Dhaval, P. S., and Chetan, G. K. (2017). Effect of rs11614913 polymorphism on mature miR196a2 expression and its target gene HOXC8 expression in human glioma. J. Mol. Neurosci. 61, 144-151. doi: 10.1007/s12031-016-0855-z

Siu-Chi Lam, C., Ng, L., Ka-Man Chow, A., Ming-Hun Wan, T., Yau, S., Shiu-Man Cheng, N., et al. (2017). Identification of microRNA 885-5p as a novel regulator of tumor metastasis by targeting CPEB2 in colorectal cancer. Oncotarget 8 , 26858-26870. doi: 10.18632/oncotarget.15844

Squadrito, M. L., Baer, C., Burdet, F., Maderna, C., Gilfillan, G. D., Lyle, R., et al. (2014). Endogenous RNAs modulate microRNA sorting to exosomes and transfer to acceptor cells. Cell Rep. 8, 1432-1446. doi: 10.1016/j.celrep.2014.07.035

Strimbu, K., and Tavel, J. A. (2010). What are biomarkers? Curr. Opin. HIV AIDS 5, 463-466. doi: 10.1097/COH.0b013e32833ed177

Swart, M., and Dandara, C. (2014). Genetic variation in the 3???-UTR of CYP1A2, CYP2B6, CYP2D6, CYP3A4, NR1I2, and UGT2B7: potential effects on regulation by microRNA and pharmacogenomics relevance. Front. Genet. 5:167. doi: 10.3389/fgene.2014.00167
Takahashi, M., Cuatrecasas, M., Balaguer, F., Hur, K., Toiyama, Y., Castells, A., et al. (2012). The clinical significance of MiR-148a as a predictive biomarker in patients with advanced colorectal cancer. PLOS ONE 7:e46684. doi: 10.1371/journal.pone.0046684

Takamizawa, J., Konishi, H., Yanagisawa, K., Tomida, S., Osada, H., Endoh, H., et al. (2004). Reduced Expression of the let-7 MicroRNAs in human lung cancers in association with shortened post-operative survival. Cancer Res. 64, 3753-3756. doi: 10.1158/0008-5472.CAN-04-0637

Thomas, M., Lieberman, J., and Lal, A. (2010). Desperately seeking microRNA targets. Nat. Struct. Mol. Biol. 17, 1169-1174. doi: 10.1038/nsmb.1921

Thompson, K. L., Boitier, E., Chen, T., Couttet, P., Ellinger-Ziegelbauer, H., Goetschy, M., et al. (2016). Absolute measurement of cardiac injury-induced microRNAs in biofluids across multiple test sites. Toxicol. Sci. 154, 115-125. doi: 10.1093/toxsci/kfw143

Thomson, D. W., and Dinger, M. E. (2016). Endogenous microRNA sponges: evidence and controversy. Nat. Rev. Genet. 17, 272-283. doi: $10.1038 / \mathrm{nrg} .2016 .20$

To, K. K. W., Robey, R. W., Knutsen, T., Zhan, Z., Ried, T., and Bates, S. E. (2009). Escape from hsa-miR-519c enables drug-resistant cells to maintain high expression of ABCG2. Mol. Cancer Ther. 8, 2959-2968. doi: 10.1158/1535-7163.MCT-09-0292

Tosar, J. P., Gámbaro, F., Sanguinetti, J., Bonilla, B., Witwer, K. W., and Cayota, A. (2015). Assessment of small RNA sorting into different extracellular fractions revealed by high-throughput sequencing of breast cell lines. Nucleic Acids Res. 43, 5601-5616. doi: 10.1093/nar/gkv432

Turchinovich, A., Weiz, L., Langheinz, A., and Burwinkel, B. (2011). Characterization of extracellular circulating microRNA. Nucleic Acids Res. 39, 7223-7233. doi: 10.1093/nar/gkr254

Venkateswaran, S., Luque-González, M. A., Tabraue-Chávez, M., Fara, M. A., López-Longarela, B., Cano-Cortes, V., et al. (2016). Novel bead-based platform for direct detection of unlabelled nucleic acids through Single Nucleobase Labeling. Talanta 161, 489-496. doi: 10.1016/j.talanta.2016. 08.072

Villarroya-Beltri, C., Gutiérrez-Vázquez, C., Sánchez-Cabo, F., Pérez-Hernández, D., Vázquez, J., Martin-Cofreces, N., et al. (2013). Sumoylated hnRNPA2B1 controls the sorting of miRNAs into exosomes through binding to specific motifs. Nat. Commun. 4:2980. doi: 10.1038/ncomms3980

Volinia, S., Calin, G. A., Liu, C.-G., Ambs, S., Cimmino, A., Petrocca, F., et al. (2006). A microRNA expression signature of human solid tumors defines cancer gene targets. Proc. Natl. Acad. Sci. U.S.A. 103, 2257-2261. doi: 10.1073/pnas.0510565103

Wang, J.-X., Zhang, X.-J., Feng, C., Sun, T., Wang, K., Wang, Y., et al. (2015). MicroRNA-532-3p regulates mitochondrial fission through targeting apoptosis repressor with caspase recruitment domain in doxorubicin cardiotoxicity. Cell Death Dis. 6:e1677. doi: 10.1038/cddis.2015.41

Wang, L.-J., He, C.-C., Sui, X., Cai, M.-J., Zhou, C.-Y., Ma, J.-L., et al. (2015). MiR-21 promotes intrahepatic cholangiocarcinoma proliferation and growth in vitro and in vivo by targeting PTPN14 and PTEN. Oncotarget 6, 5932-5946. doi: 10.18632/oncotarget. 3465

Wang, Q., Zhong, M., Liu, W., Li, J., Huang, J., and Zheng, L. (2011). Alterations of microRNAs in Cisplatin-resistant human non-small cell lung cancer cells (A549/DDP). Exp. Lung Res. 37, 427-434. doi: 10.3109/01902148.2011. 584263

Wang, X., Jiang, H., Wu, W., Zhang, R., Wu, L., Chen, H., et al. (2017). An Integrating Approach for Genome-Wide Screening of MicroRNA Polymorphisms Mediated Drug Response Alterations. Int. J. Genomics 2017, 1-7. doi: 10.1155/2017/1674827

Wang, Y., Wang, D., Xie, G., Yin, Y., Zhao, E., Tao, K., et al. (2017). MicroRNA152 regulates immune response via targeting $\mathrm{B} 7-\mathrm{H} 1$ in gastric carcinoma. Oncotarget 8, 28125-28134. doi: 10.18632/oncotarget.15924

Wei, J., Lv, L., Wan, Y., Cao, Y., Li, G., Lin, H., et al. (2015). Vps4A functions as a tumor suppressor by regulating the secretion and uptake of exosomal microRNAs in human hepatoma cells. Hepatology 61, 1284-1294. doi: $10.1002 /$ hep. 27660

Wilson, R. C., Tambe, A., Kidwell, M. A., Noland, C. L., Schneider, C. P., Doudna, J. A., et al. (2015). Dicer-TRBP complex formation ensures accurate mammalian microRNA biogenesis. Mol. Cell 57, 397-407. doi: 10.1016/j.molcel.2014.11.030 
Wu, Q., Wang, C., Lu, Z., Guo, L., and Ge, Q. (2012). Analysis of serum genomewide microRNAs for breast cancer detection. Clin. Chim. Acta 413, 1058-1065. doi: $10.1016 /$ j.cca.2012.02.016

Wynendaele, J., Bohnke, A., Leucci, E., Nielsen, S. J., Lambertz, I., Hammer, S., et al. (2010). An Illegitimate microRNA Target Site within the 3' UTR of MDM4 Affects Ovarian Cancer Progression and Chemosensitivity. Cancer Res. 70, 9641-9649. doi: 10.1158/0008-5472.CAN-10-0527

Xiong, D.-D., Lv, J., Wei, K.-L., Feng, Z.-B., Chen, J.-T., Liu, K.-C., et al. (2017). A nine-miRNA signature as a potential diagnostic marker for breast carcinoma: an integrated study of 1,110 cases. Oncol. Rep. 37, 3297-3304. doi: 10.3892/or.2017.5600

Xu, W., Zhang, Z., Zou, K., Cheng, Y., Yang, M., Chen, H., et al. (2017). MiR-1 suppresses tumor cell proliferation in colorectal cancer by inhibition of Smad3mediated tumor glycolysis. Cell Death Dis. 8:e2761. doi: 10.1038/cddis.2017.60

Xu, Z., Zeng, X., Tian, D., Xu, H., Cai, Q., Wang, J., et al. (2014). MicroRNA-383 inhibits anchorage-independent growth and induces cell cycle arrest of glioma cells by targeting CCND1. Biochem. Biophys. Res. Commun. 453, 833-838. doi: 10.1016/j.bbrc.2014.10.047

Yanaihara, N., Caplen, N., Bowman, E., Seike, M., Kumamoto, K., Yi, M., et al. (2006). Unique microRNA molecular profiles in lung cancer diagnosis and prognosis. Cancer Cell 9, 189-198. doi: 10.1016/j.ccr.2006.01.025

Yekta, S., Shih, I., and Bartel, D. P. (2004). MicroRNA-Directed Cleavage of HOXB8 mRNA. Science 304, 594-596. doi: 10.1126/science.1097434

Yoon, J.-H., Abdelmohsen, K., and Gorospe, M. (2014). Functional interactions among microRNAs and long noncoding RNAs. Semin. Cell Dev. Biol. 34, 9-14. doi: 10.1016/j.semcdb.2014.05.015

Yu, S.-L., Chen, H.-Y., Chang, G.-C., Chen, C.-Y., Chen, H.-W., Singh, S., et al. (2008). MicroRNA signature predicts survival and relapse in lung cancer. Cancer Cell 13, 48-57. doi: 10.1016/j.ccr.2007.12.008

Zhang, Q., Di, W., Dong, Y., Lu, G., Yu, J., Li, J., et al. (2015). High serum miR183 level is associated with poor responsiveness of renal cancer to natural killer cells. Tumor Biol. 36, 9245-9249. doi: 10.1007/s13277-015-3604-y

Zhao, J., Lei, T., Xu, C., Li, H., Ma, W., Yang, Y., et al. (2013). MicroRNA-187, down-regulated in clear cell renal cell carcinoma and associated with lower survival, inhibits cell growth and migration though targeting B7-H3. Biochem. Biophys. Res. Commun. 438, 439-444. doi: 10.1016/j.bbrc.2013.07.095
Zhao, Y., Song, Y., Yao, L., Song, G., and Teng, C. (2017). Circulating microRNAs: promising biomarkers involved in several cancers and other diseases. DNA Cell Biol. 36, 77-94. doi: 10.1089/dna.2016.3426

Zheng, J., Deng, J., Xiao, M., Yang, L., Zhang, L., You, Y., et al. (2013). A sequence polymorphism in miR-608 predicts recurrence after radiotherapy for nasopharyngeal carcinoma. Cancer Res. 73, 5151-5162. doi: 10.1158/0008-5472.CAN-13-0395

Zhou, B., Xu, H., Xia, M., Sun, C., Li, N., Guo, E., et al. (2017). Overexpressed miR9 promotes tumor metastasis via targeting E-cadherin in serous ovarian cancer. Front. Med. 11, 214-222. doi: 10.1007/s11684-017-0518-7

Zhou, H., Arcila, M. L., Li, Z., Lee, E. J., Henzler, C., Liu, J., et al. (2012). Deep annotation of mouse iso-miR and iso-moR variation. Nucleic Acids Res. 40, 5864-5875. doi: 10.1093/nar/gks247

Zhu, H.-T., Dong, Q.-Z., Wang, G., Zhou, H.-J., Ren, N., Jia, H.-L., et al. (2012). Identification of suitable reference genes for qRT-PCR analysis of circulating microRNAs in hepatitis B virus-infected patients. Mol. Biotechnol. 50, 49-56. doi: 10.1007/s12033-011-9414-6

Zhu, H., Zhou, X., Ma, C., Chang, H., Li, H., Liu, F., et al. (2015). Low Expression of miR-448 Induces EMT and promotes invasion by regulating ROCK2 in hepatocellular carcinoma. Cell. Physiol. Biochem. 36, 487-498. doi: $10.1159 / 000430114$

Zhu, S., Si, M.-L., Wu, H., and Mo, Y.-Y. (2007). MicroRNA-21 targets the tumor suppressor gene tropomyosin 1 (TPM1). J. Biol. Chem. 282, 14328-14336. doi: 10.1074/jbc.M611393200

Conflict of Interest Statement: The authors declare that the research was conducted in the absence of any commercial or financial relationships that could be construed as a potential conflict of interest.

Copyright (c) 2017 Detassis, Grasso, Del Vescovo and Denti. This is an openaccess article distributed under the terms of the Creative Commons Attribution License (CC BY). The use, distribution or reproduction in other forums is permitted, provided the original author(s) or licensor are credited and that the original publication in this journal is cited, in accordance with accepted academic practice. No use, distribution or reproduction is permitted which does not comply with these terms. 